\title{
Organic Amendments Alter Soil Hydrology and Belowground Microbiome of Tomato (Solanum lycopersicum)
}

\author{
Taylor Readyhough, Deborah A. Neher* ${ }^{(D)}$ and Tucker Andrews
}

check for updates

Citation: Readyhough, T.; Neher, D.A.; Andrews, T. Organic Amendments Alter Soil Hydrology and Belowground Microbiome of Tomato (Solanum lycopersicum). Microorganisms 2021, 9, 1561. https://doi.org/10.3390/ microorganisms 9081561

Academic Editors: Shiri Freilich, Mark Mazzola and Tracey Somera

Received: 4 June 2021

Accepted: 19 July 2021

Published: 22 July 2021

Publisher's Note: MDPI stays neutral with regard to jurisdictional claims in published maps and institutional affiliations.

Copyright: (c) 2021 by the authors. Licensee MDPI, Basel, Switzerland. This article is an open access article distributed under the terms and conditions of the Creative Commons Attribution (CC BY) license (https:// creativecommons.org/licenses/by/ $4.0 /)$.
Department of Plant and Soil Science, University of Vermont, Jeffords Hall, Burlington, VT 05405, USA; treadyhough@gmail.com (T.R.); tucker.andrews@uvm.edu (T.A.)

* Correspondence: dneher@uvm.edu; Tel.: +1-802-656-0474

\begin{abstract}
Manure-derived organic amendments are a cost-effective tool that provide many potential benefits to plant and soil health including fertility, water retention, and disease suppression. A greenhouse experiment was conducted to evaluate how dairy manure compost (DMC), dairy manure compost-derived vermicompost (VC), and dehydrated poultry manure pellets (PP) impact the tripartite relationship among plant growth, soil physiochemical properties, and microbial community composition. Of tomato plants with manure-derived fertilizers amendments, only VC led to vigorous growth through the duration of the experiment, whereas DMC had mixed impacts on plant growth and PP was detrimental. Organic amendments increased soil porosity and soil water holding capacity, but delayed plant maturation and decreased plant biomass. Composition of bacterial communities were affected more by organic amendment than fungal communities in all microhabitats. Composition of communities outside roots (bulk soil, rhizosphere, rhizoplane) contrasted those within roots (endosphere). Distinct microbial communities were detected for each treatment, with an abundance of Massilia, Chryseolinea, Scedosporium, and Acinetobacter distinguishing the control, vermicompost, dairy manure compost, and dehydrated poultry manure pellet treatments, respectively. This study suggests that plant growth is affected by the application of organic amendments not only because of the soil microbial communities introduced, but also due to a synergistic effect on the physical soil environment. Furthermore, there is a strong interaction between root growth and the spatial heterogeneity of soil and root-associated microbial communities.
\end{abstract}

Keywords: compost amendment; dairy manure compost; microbial community; poultry pellets; vermicompost; water holding capacity; water potential

\section{Introduction}

Reducing the volume of organic wastes that end up in landfills is a critical challenge in the battle to mitigate climate change [1]. Using manure and other agricultural biproducts as a fertilizer or soil conditioner provides a sustainable solution for reducing waste and minimizing emissions while improving soils and recycling nutrients for plant growth. Over the past two decades, use of manure-derived fertilizer has increased on vegetable farms, much of which can be attributed to an increase in composted manure application [2].

Growers utilize manure-derived fertilizers and other organic amendments as a costeffective tool to provide crop nutrition [3], stimulate microbial activity [4], manage plant pathogens [5], and improve soil physical and hydrological properties [6]. Despite their cost-effectiveness and availability, raw manures are generally avoided because they may emit volatile organic acids that are phytotoxic [5].

Compost is the product of a controlled aerobic process that degrades organic waste to stable material [7] with the resident microbial community mediating the biodegradation and conversion processes [8]. The USDA National Organic Program requires that compost piles maintain a thermophilic phase (maintain temperatures between 55 and $77^{\circ} \mathrm{C}$ ) for a minimum of 15 days and are turned a minimum of five times to ensure lethal conditions 
for resident pathogens [9] in windrow-produced compost. Alternatively, vermicomposting is a non-thermophilic composting process that involves joint action by earthworms and microorganisms [10]. Given the absence of a thermophilic stage, vermicomposting alone does not meet organic certification standards for processing manure. Compost-derived vermicompost, however, overcomes this limitation by combining the thermophilic phase of traditional windrow composting (thus meeting pathogen reduction standards) with a secondary vermicomposting curing phase. For brevity, we refer to this dairy manure compost-derived vermicompost simply as "vermicompost".

Organic amendment is a broad term that includes manure-derived fertilizers that are not composted but instead heat-treated to eliminate pathogens and allow for application during the crop growing season [11]. This process is not synonymous with the successional phases and biological reactions that define composting [7], and the resulting product demonstrates very different physical, chemical, and biological properties [8]. For example, dehydrated poultry manure pellets, derived from a mix of manure, feathers, and bedding, are ground, heat-treated, and pelletized for commercial use. However, non-composted poultry manure-derived products can contain pathogens, heavy metals, antibiotics, and antibiotic-resistant genes that pose a threat to plant, human, and environmental safety [12].

There are two mechanisms by which compost can affect a soil microbiome: by modifying the abiotic soil environment and by adding microbes present in the compost to the soil. Application of organic amendments to soil can induce very different responses that are dependent on properties of the materials themselves. Organic amendments modify physical properties of the soil to which they are applied by decreasing bulk density and increasing soil organic matter, soil porosity, water infiltration, and water holding capacity [13]. These factors impact the amount of water a soil can hold in soil pore spaces. Both too little or too much water in soil pore spaces can be detrimental, leading to either drought stress and/or anaerobic conditions, respectively [14]. Changes to soil pore size distribution resulting from the application of these materials [15] directly impact habitat availability for different types of soil microorganisms. Among the most influential factors in shaping soil microbial community composition are soil water content [16] and the inherent physiochemical properties of organic amendments [17], which ultimately modify soil structure and hydrologic dynamics.

The microbial community composition of composts is determined by differences in feedstock (i.e., carbon and nitrogen sources), method (i.e., windrow, aerated static pile, vermicompost), and duration (i.e., successional stage, maturation) [8]. Each of these factors shape microbial communities by favoring organisms with varying affinities for different substrates or environmental conditions [5]. The microbial community of the finished compost, in turn, significantly influences the microbial community of the soil to which it is applied [18]. Microbial communities present in these materials possess a variety of tactics to compete with and defend against the resident soil microbial community for habitat and resources once incorporated into soil. The inoculation or stimulation of certain bacteria or fungi with known benefits to soil or plant health, referred to as beneficial microorganisms (BMs) or plant growth-promoting rhizobacteria (PGPR), are significant potential benefits of organic amendment application. The ability of BMs to compete with pathogens directly, via parasitism, antagonism, or antibiotic production, or indirectly, by inducing systemic defense responses in plants, is well documented (e.g., [19,20]. BMs and pathogens compete for habitat and resources in the areas immediately surrounding, on the surface of, or inside the tissue of plant roots [21].

While microorganisms compete for habitat and resources, plants themselves are not idle observers. The area immediately surrounding the plant root is inhabited by a unique population of microorganisms that are attracted to chemicals released from plant roots. Plants have developed the ability to modify the chemical composition in root exudates to favor organisms with affinities for certain compounds [22]. Microorganisms rapidly utilize these compounds as they are secreted from roots, fostering a highly active microbial community in the area immediately surrounding the root. Plants expend a considerable 
amount (up to $40 \%$ ) of their photosynthesis-derived carbon to foster interactions with microorganisms in the rhizosphere [22]. In return, these microorganisms increase the availability and uptake of plant nutrients [23,24], induce changes in root growth [25], enhance plant tolerance to abiotic stress [24,26], and promote plant growth by synthesizing and excreting phytohormone analogs $[27,28]$.

Communities of soil microbes are modified by the presence of plant roots and can be divided into four compartments or microhabitats: bulk soil, rhizosphere, rhizoplane, and endo(rhizo)sphere [29]. The factors responsible for shaping microbial community composition differ among each of these microhabitats. Bulk soil contains a reservoir of microorganisms with a community shaped primarily by soil type, vegetation history, and environmental factors [29]. In the rhizosphere, roots deposit carbon and organic acids, thus adding microbial food and reducing $\mathrm{pH}$, and deplete the immediate environment of moisture, oxygen, and nutrients [29]. Rhizoplane microorganisms are selected from the rhizosphere largely based upon their ability to compete for a limited habitat and resources on the root surface [20,21,29]. Finally, community composition in the endosphere is also largely based upon abilities and characteristics of the organisms themselves. These organisms display the greatest level of specialization, having developed the ability to physically invade and inhabit root tissue, although their selection and enrichment is limited to the organisms present in other pools [29,30].

We know that certain manure-based fertilizers exhibit plant growth promoting properties, but we do not fully understand the complex interactions among soil physical properties, microbes, and plants that occur after their amendment and how these interactions shape agricultural outcomes. Application of organic amendments changes community composition at nearly all levels of taxonomic rank, from phylum to subspecies [31-35]. Nonetheless, differences in soil types, crop species, and properties of organic amendments make it difficult to compare results among studies.

The study was designed to test the hypothesis that manure-based vermicompost promotes plant growth at least as well as mineral fertilizer and is superior to windrowbased dairy manure compost or heat-treated poultry pellets. We conducted a greenhouse experiment to grow tomato (Solanum lycopersicum) with three organic amendment treatments (dairy manure compost, dairy manure-derived vermicompost, dehydrated poultry manure pellets) and a conventionally fertilized control. We measured plant growth and soil physical properties, and characterized the bacterial and fungal communities of the compartmentalized root microbiome using high-throughput amplicon sequencing of $16 \mathrm{~S}$ rRNA and ITS-1 genes, respectively.

\section{Materials and Methods}

\subsection{Experimental Design}

We chose tomato because it is a popular cash crop grown both in field and hoophouses (for season extension). Furthermore, it allowed comparison to prior studies that focused on growth promotion by vermicompost [36]. Seeds of tomato (Solanum lycopersicum) varietal "Mountain Fresh Plus F1" (Johnny's Selected Seeds, Winslow, ME, USA) were planted into separate 72 cell trays with a growing mixture amended as one of four treatments: dairy manure compost (DMC), dairy manure-derived vermicompost (VC), dehydrated poultry manure pellets (PP), and an untreated (conventionally fertilized) control (UC). After 30 days, 10-15 cm tall seedlings were transplanted into C100 (0.4 L), C200 (0.9 L), and C300S (1.6 L) Elite Custom blow-molded nursery pots (Nursery Supplies, Chambersburg, PA, USA) filled with field soil amended as one of the four treatments: DMC, VC, PP, and UC. Plants were grown in containers of three incrementally larger volumes to allow unrestricted root growth in those grown for one, two, or three weeks after transplant. Single plants were arranged as experimental units in blocks by harvest time in a completely randomized design. The entire experiment was repeated twice. Ten replicate plants were harvested from each treatment at each of four times $(0,7,14$ and 21 days after transplant) for a total of 160 experimental units per experimental replication. Of the 10 replicate 
plants destructively harvested per treatment-time combination, five were assessed for morphology and three sampled for characterization of the root microbiome with two extra replicates available as backups in the event of error. For each plant root system, multiple subsamples were collected from each of four microhabitats: bulk soil, rhizosphere, rhizoplane, and endosphere.

\subsection{Growth Conditions}

Seedlings were grown in a greenhouse at $21.7^{\circ} \mathrm{C}$ day and $17.8^{\circ} \mathrm{C}$ night temperatures with a range of $2.2^{\circ} \mathrm{C}$. Root-zone bench heating was provided at $26.7^{\circ} \mathrm{C}$ to increase the probability of germination and encourage root growth. Mature seedlings were transplanted and transferred to an adjacent greenhouse module at $23.9^{\circ} \mathrm{C}$ day and $18.3^{\circ} \mathrm{C}$ night temperatures with a range of $1.65^{\circ} \mathrm{C}$. High-pressure sodium lamps provided supplemental lighting to maintain a photoperiod of $16 \mathrm{~h}$ from dawn throughout the experiment. Containers were spaced at appropriate distances to prevent crowding or shading between plants.

Containers with field soil were irrigated by hand two to three times per week with greenhouse tap water of $\mathrm{pH} 7$ and electrical conductivity of $0.2 \mu \mathrm{S} / \mathrm{cm}$. Soil volumetric water content (VWC) was used to dictate irrigation practices with irrigation events targeted for the VWC value observed at a matric potential of $-300 \mathrm{kPa}$ in each soil. At the time of each watering event, VWC was measured by total domain refractometry (TDR) using a ThetaProbe ML3 Soil Moisture Sensor and HH2 Soil Moisture Reader (Delta-T Devices, Cambridge, UK).

\subsection{Organic Amendments}

The treatments chosen are popularly used amendments in field vegetable production in the northeastern U.S. Vermicompost and dairy compost were obtained from Worm Power (Avon, NY). Worm Power compost feedstock is sourced from a local cow dairy that feeds a nutritionally consistent ration and provided sawdust bedding. Worm Power product was used because it is the same source as that used in earlier research [36,37]. Dairy manure with a small amount of silage is composted in an aerated static pile for an average of 40 days before the material is layered on top of a continuous flow vermiculture bed. The bed is densely populated with composting worms (Eisenia fetida) that digest the material for approximately six weeks before it is harvested as finished vermicompost. Both dairy manure-based products are produced with an identical recipe that is consistent throughout the year. These treatments were applied at the rate of $20 \%$ volume per volume of soil, as suggested by prior research [36,38]. Dehydrated, granulated 3-2-3 poultry manure purchased from Espoma (Millville, NJ, USA) was mixed 10\% by volume with vermiculite to increase aeration before adding $20 \%$ volume of the mixture to soil. Control treatments were supplemented with 15-9-12 Smart-Release Plant Food Plus Outdoor \& Indoor (Scotts Miracle-Gro Company, Marysville, OH, USA) at $8.75 \mathrm{~g}$ per liter of soil as suggested by the manufacturer.

\subsection{Growing Media}

Fort Vee growing mix (Vermont Compost Company, Montpelier, VT, USA) served as the base medium for germination and seedling growth. The growing mix was amended in a volumetric ratio unique to treatment (Table 1). These materials were standardized for $\mathrm{N}$ content based on volume as a horticulturist would use materials, but which translates into unequal levels based on weight (Table 1). 
Table 1. Composition of growing medium used in plug trays for germination and seedling growth.

\begin{tabular}{cccc}
\hline Treatment & \% Volume Fort Vee & $\begin{array}{c}\text { \% Volume Organic } \\
\text { Amendment }\end{array}$ & $\begin{array}{c}\text { Adjusted N } \\
\left.\text { (g L L }^{-1}\right)\end{array}$ \\
\hline Control & 100 & 0 & 1.3 \\
Vermicompost & 80 & 20 & 7.5 \\
Dairy manure & 80 & 20 & 7.5 \\
compost & 80 & $10^{*}$ & 5.5 \\
\hline Poultry pellets &
\end{tabular}

* $10 \%$ of commercial product in the soil with an additional $10 \%$ vermiculite.

Field soil was used in the containers for the transplants. Approximately 0.75 cubic meters of field soil was collected from a local agricultural research site $\left(44^{\circ} 26^{\prime} 39.0^{\prime \prime} \mathrm{N}\right.$, $\left.73^{\circ} 11^{\prime} 23.9^{\prime \prime} \mathrm{W}\right)$. Soil was steam pasteurized in a $14 \mathrm{MS}$ Media Steamer Cart using a 210 Steam Aerator (Hummert International, Earth City, MO, USA) at $165^{\circ} \mathrm{C}$ for four hours on two consecutive days to avoid the possibility of soil pathogens as a confounding factor. Steamed soil was rested for a few weeks to equilibrate in gas emission and microbial community before commencing with the experiment. This soil has been well characterized for related experiments (Neher, 2019). Indigenous microorganisms were extracted from the raw soil via soil extract and re-applied to the pasteurized soil after allowing the soil to cool for several days. Briefly, soil extract was prepared by diluting $250 \mathrm{~g}$ of soil in $2.5 \mathrm{~L}$ deionized water in a four liter Erlenmeyer flask. The flask was covered and placed in a C1 Orbital Platform Shaker (New Brunswick Scientific, Edison, NJ, USA) for $24 \mathrm{~h}$. The shaken solution was vacuum filtered to $10 \mu \mathrm{m}$ in a Buchner funnel. The filtered solution was diluted to $5 \mathrm{~L}$ and applied to the pasteurized soil in the steam cart once it had cooled. Lastly, the soil was sieved through a $2 \times 2 \mathrm{~cm}$ screen to remove large organic and mineral debris and to homogenize the base soil mixture. Ten percent $(v / v)$ vermiculite was added to the base soil mixture to provide structure and promote drainage (Table 2).

Table 2. Composition of soil mixtures used in containers for transplants.

\begin{tabular}{|c|c|c|c|c|}
\hline Treatment & $\begin{array}{c}\% \text { Volume Field } \\
\text { Soil }\end{array}$ & $\begin{array}{c}\% \text { Volume } \\
\text { Amendment }\end{array}$ & $\begin{array}{c}\% \text { Volume } \\
\text { Vermiculite }\end{array}$ & $\begin{array}{l}\text { Bulk Density } \\
\left(\mathrm{g} / \mathrm{cm}^{3}\right)\end{array}$ \\
\hline Control & 90 & 0 & 10 & 0.99 \\
\hline Vermicompost & 70 & 20 & 10 & 0.88 \\
\hline $\begin{array}{l}\text { Dairy manure } \\
\text { compost }\end{array}$ & 70 & 20 & 10 & 0.83 \\
\hline Poultry pellets & 70 & 10 & $20 *$ & 0.85 \\
\hline
\end{tabular}

* $10 \%$ vermiculite added to increase drainage.

\subsection{Soil Physical Properties}

Pore size distribution of the soil was determined with a water release curve for each treatment mixed with soil. Samples were gently packed into $5 \mathrm{~cm}$ diameter $\times 7.5 \mathrm{~cm}$ tall cylinders on a porous ceramic pressure plate (Soil Moisture Equipment Corp, Santa Barbara, CA, USA). Soils were saturated for $24 \mathrm{~h}$ before pressure was applied at an amount equivalent to soil matric potentials of $-40,-100,-200,-300$, and $-500 \mathrm{kPa}$. These matric potentials are representative of field capacity $(-30 \mathrm{kPa})$ and gradually decreasing water availability to water deficit stress in common crops $(-200$ to $-500 \mathrm{kPa})$. A single $1 \mathrm{~cm}$ diameter $\times 7 \mathrm{~cm}$ tall soil core was taken from each of three replicate cylinders per treatment after $48 \mathrm{~h}$ at a specific matric potential. These soil cores were weighed fresh and after drying at $90{ }^{\circ} \mathrm{C}$ for $72 \mathrm{~h}$ as a measure of gravimetric water content at each matric potential. Water released at a range of matric potentials provided a calibration curve for the time domain reflectometry (TDR) probe (Figure S1). 


\subsection{Plant Growth}

Plant growth was measured as total plant biomass (shoots and roots) and root length density (RLD) was measured as a proxy for the probability of roots intercepting microbes originating from compost mixed into soil. Each plant was severed at the hypocotyl upon harvest. The belowground root mass was carefully separated from the soil mixture in a $20 \mathrm{~L}$ bucket of tap water by gently massaging the soil away from the roots. The washed root mass was cleaned with a fine mist of water to remove any debris. Both the aboveground and belowground biomass were dried at $60{ }^{\circ} \mathrm{C}$ for $96 \mathrm{~h}$ and summed for expression as grams of total dry mass per plant. Root length density (RLD) per plant was measured by placing roots in $250 \mathrm{~mL}$ distilled water within a $22 \times 28 \mathrm{~cm}$ plexiglass tray on an Epson Perfection V370 scanner (Seiko Epson Corporation, Suwa, Nagano, Japan). A highresolution digital image of the sample was manipulated using AxioVision SE64 software (Zeiss Group International, Oberkochen, Germany) to express RLD as length of root per volume of soil ( $\mathrm{cm}$ root length per $\mathrm{cm}^{3}$ soil).

\subsection{Root Microbiome}

Roots of turgid plants were harvested consistently from soil that had not been watered for at least $4 \mathrm{~h}$. Belowground samples were subdivided along a spatial gradient for comparison of microorganisms residing in four microhabitats: bulk soil, rhizosphere, rhizoplane, and endosphere [29]. The root mass for each plant was removed from its container over a sterile metal collection basin to prevent cross contamination. Bulk soil that freely dislodged from the root mass during removal from the container was collected, from which three $0.04 \mathrm{~g}$ subsamples were taken. The root mass was gently shaken over a second basin to dislodge most soil from the roots. The rhizosphere soil that remained intact with the root was sampled in triplicate using a sterile cotton swab dipped in twice-autoclaved MilliQ (Millipore Sigma, Burlington, MA, USA) filtered water. Each cotton swab covered with rhizosphere soil was cut from the swab spindle with flame-sterilized scissors and placed into $2 \mathrm{~mL}$ polypropylene microcentrifuge tubes with caps (Fisher Scientific International, Hampton, NH, USA) that were briefly vortexed and sonicated for $20 \mathrm{~min}$ in a VWR Model 150D sonicator bath (VWR International, West Chester, PA, USA). The cotton swab was removed and the suspension with soil was kept as the representative subsample of the rhizosphere community. Finally, five $2 \mathrm{~cm}$ long growing root tips were excised from each plant using flame-sterilized scissors. Excised roots from each plant were pooled, rinsed in twice-autoclaved Milli-Q water, and sonicated for $20 \mathrm{~min}$. The post-sonication suspension was kept as the representative subsample of the rhizoplane community removed from the root (endosphere). With the exception of endosphere samples, each of three subsamples per microhabitat (bulk soil, rhizosphere, rhizoplane) per plant were transferred, in a dark room, to a sterile $2 \mathrm{~mL}$ polypropylene microcentrifuge tube filled with $1.4 \mathrm{~mL}$ sterile-filtered phosphate buffer saline containing $3.5 \mu \mathrm{L}$ of $40 \mu \mathrm{M}$ propidium monoazide (PMA) dye solution (Biotium, Inc., Fremont, CA, USA). Samples were prepared in triplicate with small volumes of soil and solution to avoid adsorption of PMA to soil particles and allow the solution to mix thoroughly during light exposure, ensuring a complete photolytic reaction of the PMA $[39,40]$. Endosphere samples were removed from the solution with flame-sterilized forceps and transferred to QIAGEN PowerBead Tubes from a DNeasy PowerSoil Kit (QIAGEN, Germantown, MD, USA), and immediately stored at $-80^{\circ} \mathrm{C}$.

\subsection{PMA Photolysis and DNA Extraction}

PMA photolysis and DNA extraction methods followed protocols described by Carini et al. [39] and Lauber et al. [41], respectively. Briefly, a $600 \mathrm{~W}$ halogen lamp was placed $20 \mathrm{~cm}$ above an ice bath secured on a C1 Orbital Platform Shaker (New Brunswick Scientific, Edison, NJ, USA). Tubes containing bulk soil and rhizosphere samples were placed on ice, shaken, and illuminated $30 \mathrm{~s}$ on/30 s off four consecutive times. Shaking ensured that the contents of the tubes experienced even light exposure. The ice bath served 
to secure the tubes, keep the solutions cool from the heat of the lamp, and provide reflection of light. After incubation, tubes were stored at $-80{ }^{\circ} \mathrm{C}$ until DNA was extracted.

DNA was extracted from bulk soil, rhizosphere, rhizoplane, and endosphere samples using a DNeasy PowerSoil Kit (QIAGEN, Germantown, MD, USA). Specifically, $850 \mu \mathrm{L}$ from each $2 \mathrm{~mL}$ sample tube was transferred to PowerBead Tubes, placed in a $65{ }^{\circ} \mathrm{C}$ water bath for $10 \mathrm{~min}$, and then shaken horizontally for $2 \mathrm{~min}$ at maximum speed with the MoBio vortex adapter. A quantity of $500 \mu \mathrm{L}$ of the bead-beaten solution was transferred, undergoing subsequent steps to isolate and purify DNA as directed by the manufacturer. Triplicate subsamples of bulk soil (per plant), rhizosphere (per plant), rhizoplane (per treatment-time combination), and endosphere (per treatment-time combination) were extracted individually. The resulting purified DNA was pooled for each microhabitat to obtain a sufficient concentration of DNA for sequencing. Pooled $300 \mu \mathrm{L}$ purified DNA samples were shipped overnight express to the University of Colorado at Boulder for amplicon sequencing.

\subsection{Amplicon Sequencing}

Samples were amplified using 515F/806R primers targeted for the V4 region of the 16S rRNA gene for bacteria and archaea, and ITS-1/ITS-2 primers to amplify the ITS-1 gene for fungi. Samples were amplified in triplicate and adjusted to equimolar concentrations. One microliter of genomic DNA was added to $13 \mu \mathrm{L}$ of PCR-grade water, $10 \mu \mathrm{L}$ of Prime Hot Master Mix, $0.5 \mu \mathrm{L}$ of reverse primers, and $0.5 \mu \mathrm{L}$ of forward primers. PCR was carried out in 35 thermocycles of $94{ }^{\circ} \mathrm{C}$ for $45 \mathrm{~s}, 50{ }^{\circ} \mathrm{C}$ for $60 \mathrm{~s}$, and $72{ }^{\circ} \mathrm{C}$ for $90 \mathrm{~s}$.

Quality filtering and clustering of sequences into exact sequence variants (ESVs) was performed using the DADA2 pipeline [42]. The DADA2 pipeline contains a pre-processing step which demultiplexes with the idemp program, removes sequences with ambiguous bases, and removes any primers with cutadapt [43]. Data were then filtered and trimmed for quality, sequence variants inferred, chimeras removed, singletons removed, and taxonomy assigned using the Greengenes v13.8 database for bacterial and archaeal 16S rRNA gene sequences [44] or the UNITE v7.2 fungal ITS database for fungi [45]. Mitochondrial, chloroplast, and eukaryote sequences were removed from $16 \mathrm{~S}$ data. ESVs not assigned to kingdom or phylum were removed prior to downstream analyses. The $16 \mathrm{~S}$ data were rarefied to 11,441 sequences per sample, trimming the data from 187 to 174 samples. The ITS data were rarefied to 1028 counts, trimming the data from 185 to 168 samples. The final $16 S$ and ITS analyses included 18,038 and 887 ESVs, respectively.

\subsection{Statistical Analysis}

Plant growth data were analyzed as a full model two-way analysis of variance (ANOVA) with plant phenology (sampling week) and treatment as independent variables. A linear regression was performed to quantify the association between volumetric water content (measured by TDR) and water potential. Plant available water was analyzed as a one-way ANOVA with treatment as an independent variable followed by a Tukey post-hoc means comparison. The ANOVAs and linear regression were performed using GraphPad Prism Ver. 9.1.2. (https:/ / www.graphpad.com/, accessed on 7 July 2021).

The mctoolsr package in RStudio Version 1.1.463 (https:/ / github.com/leffj/mctoolsr, accessed on 1 June 2021) was used to create plots of richness (number of unique ESVs per sample) and biplots of principal coordinate analyses (PCoA) using Bray-Curtis dissimilarity matrices. Permutational multivariate analysis of variance performed in R provided pseudo-F- and $p$-values from Monte Carlo permutation tests between treatments and root microbiomes with harvest time as a block. Post hoc comparisons using Kruskal-Wallis tests between factor pairs provided $\mathrm{R}^{2}$ and false discovery rate (FDR) corrected $p$-values using the adonis function in the R package vegan. 


\section{Results}

\subsection{Plant Growth}

Dry total plant biomass varied among harvest times $(p \leq 0.0001)$, treatments $(p \leq 0.0001)$, and the interaction of harvest time and treatment $(p \leq 0.0001)$ (Figure 1). Plants of the UC treatment had the greatest total plant biomass at each harvest time. Total plant biomass decreased progressively with amendment of VC, DMC, and PP. The magnitude of differences among treatments increased through time. The pattern was similar whether expressed as plant height or total biomass.

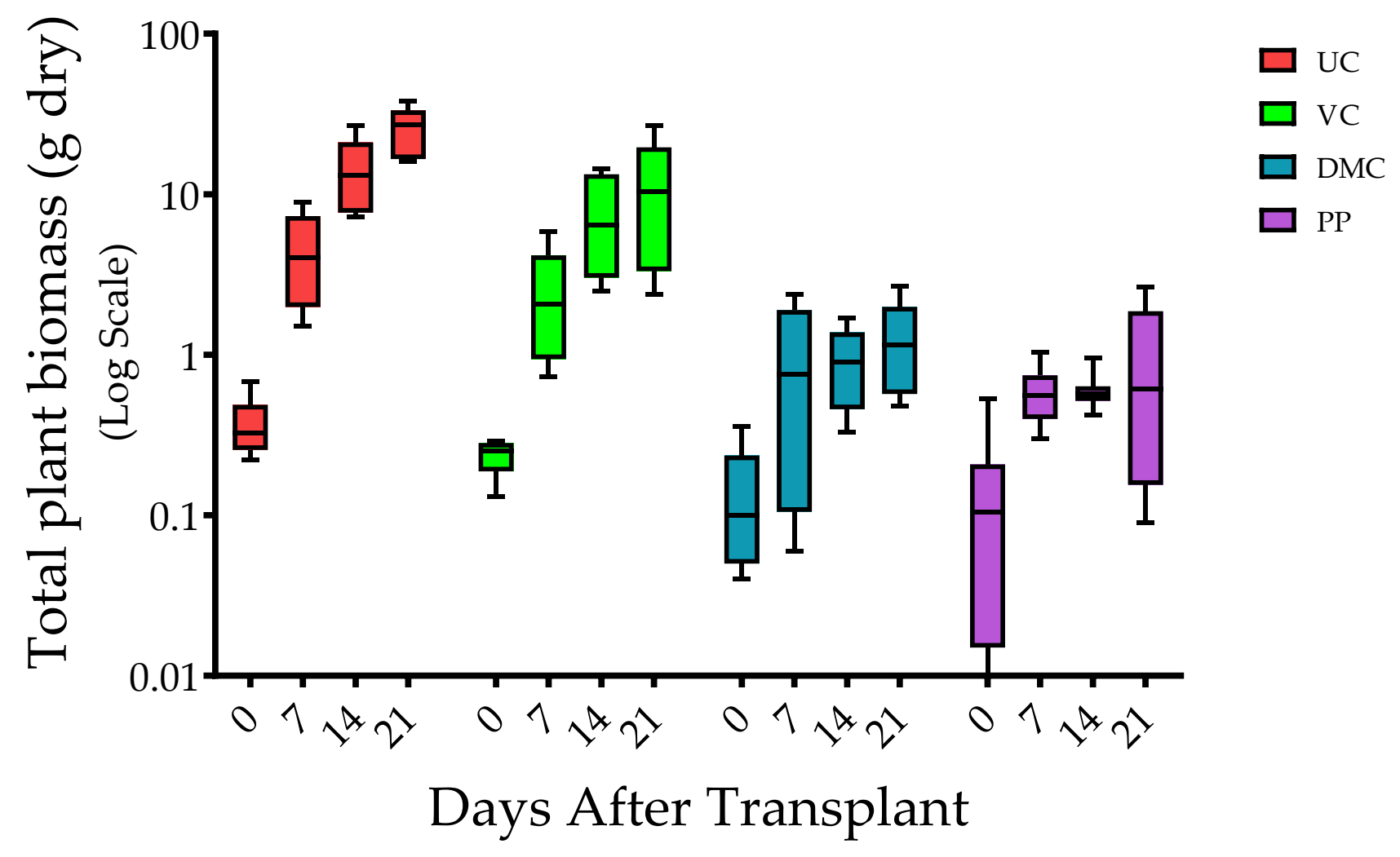

Figure 1. Box and whisker plot of total dry biomass of plants at $0,7,14$, and 21 days post-transplant $(n=10)$. The box represents 25th, 50th (median), and 75th percentiles, and the whiskers represent minimum to maximum values. Treatments represent growing mix and soil with amendment of vermicompost (VC, 20\% v/v), dairy manure compost (DMC, 20\% v/v), or dehydrated poultry manure pellets (PP, $10 \% v / v)$ compared to an untreated (conventional fertilizer) control (UC).

Root length density (RLD) differed among harvest times $(p \leq 0.0001)$ and treatments $(p \leq 0.0001)$ but not the interaction of time and treatment $(p=0.8752)$ (Figure 2). Plants of the UC treatment had the greatest RLD at each harvest time. RLD of seedlings decreased progressively with amendment of DMC, VC, and PP. RLD decreased among all treatments after transplant. RLD decreased progressively with increasing days after transplant among the plants in the DMC and PP treatments (Figure 2). 


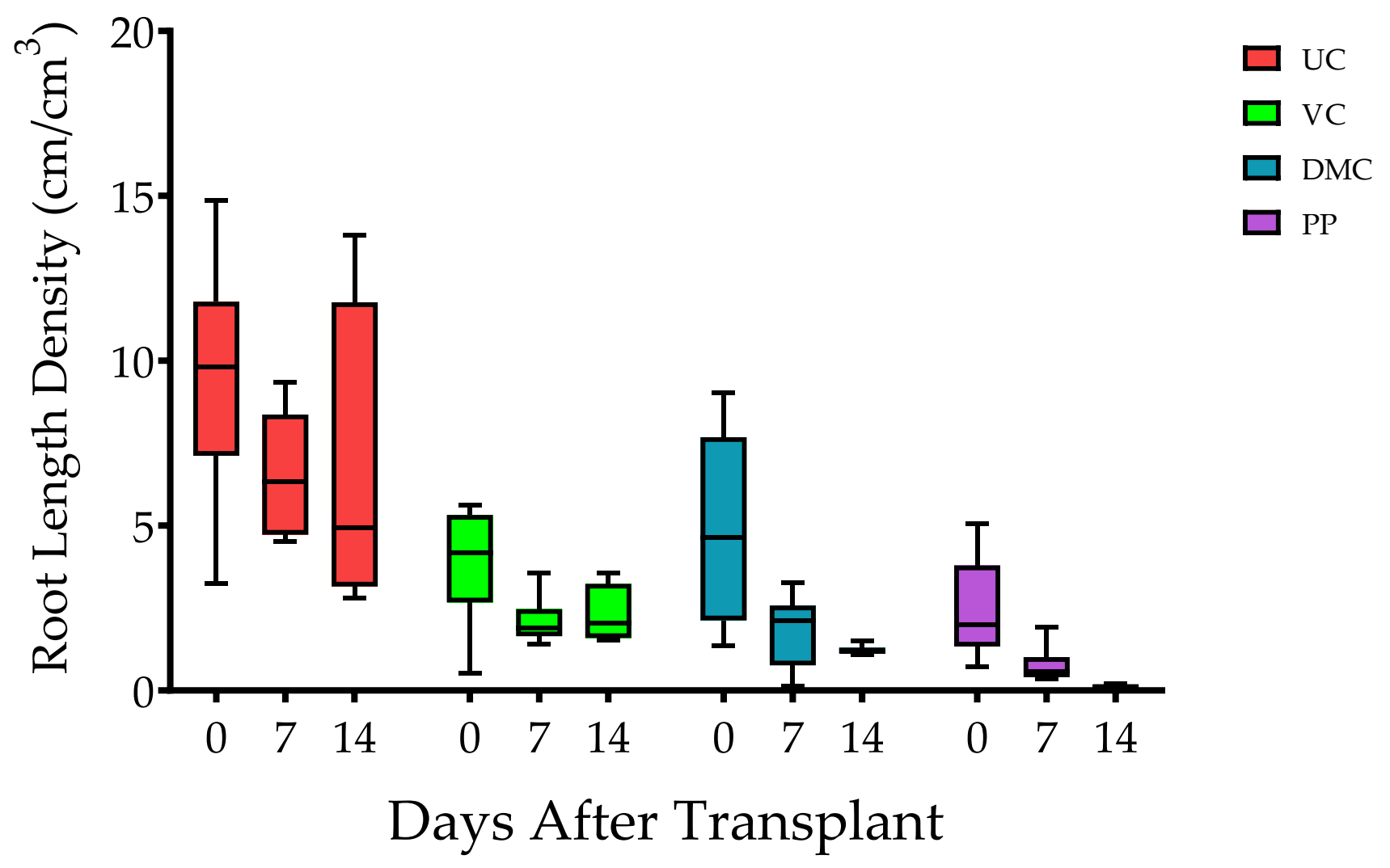

Figure 2. Box and whisker plot of root length density through time $(n=5)$. The box represents 25 th, 50 th (median), and 75th percentiles, and the whiskers represent minimum to maximum values. Error bars represent standard error of the mean. Treatments represent growing mix and soil with amendment of vermicompost (VC, 20\% $v / v)$, dairy manure compost $(\mathrm{DMC}, 20 \% v / v)$, or dehydrated poultry manure pellets (PP, 10\% v/v) in comparison to an untreated (conventional fertilizer) control (UC).

\subsection{Soil Physical and Hydrological Properties}

Water release at defined matric potentials was associated linearly with TDR probe measurements (Figure S1). Although TDR probe measurements were precise, they consistently underestimated gravimetric water content by approximately $11 \%$. Plant available water content was least in the UC, intermediate in DMC and VC, and greatest in PP treatments $(p \leq 0.0001)$. UC soil had the least total pore space, total water content, and plant available (between -40 and $-500 \mathrm{kPa}$ ) water content (Figure 3). Soils treated with organic amendments were more porous than the UC and held more plant available and unavailable water content. Soil amended with VC had similarly greater water holding capacity as soil amended with DMC $(p=0.5544)$. Soil amended with PP contained relatively little air $(8 \%)$ compared to water $(92 \%)$ in pore spaces. 


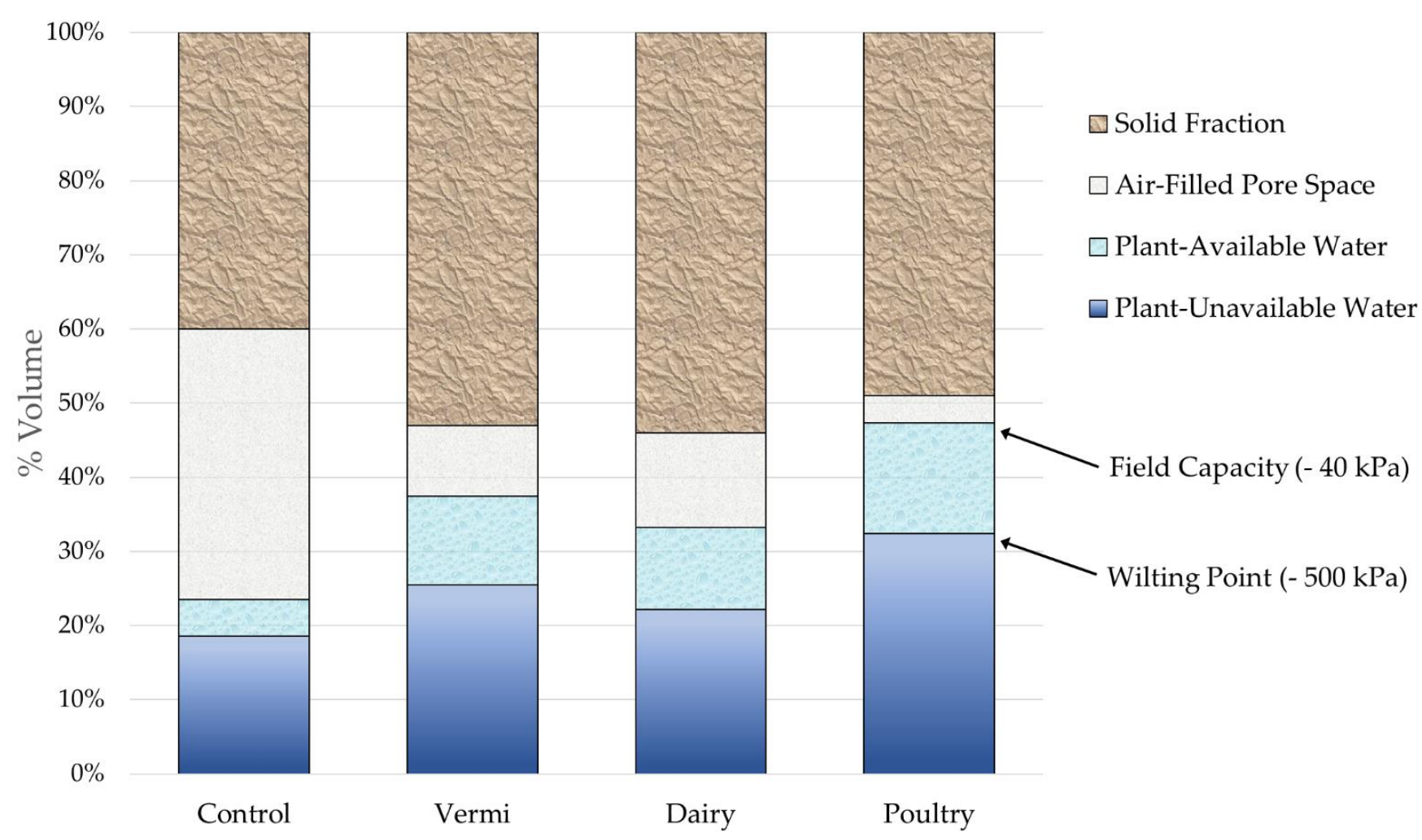

Figure 3. Solid, air, and water fractions of soils with or without organic amendments as a percentage of total volume. Values represent means $(n=3)$. Total volume of core $=147.44 \mathrm{~cm}^{3}$. Treatments represent soil amended with vermicompost $(\mathrm{VC}$, $20 \% v / v$ ), dairy manure compost (DMC, 20\% v/v), or dehydrated poultry manure pellets (PP, 10\% v/v) compared to an untreated (conventional fertilizer) control (UC). Field capacity is the amount of water content held in soil after excess water has been drained by gravity. Wilting point represents soil water that is no longer extractable by plants because it is held too tightly to soil particles by capillary action.

\section{3. $16 S$ Community Composition}

$16 \mathrm{~S}$ community composition differed among amendments (pseudo- $\mathrm{F}=19.9, p=0.001$ ) and microhabitats (pseudo- $\mathrm{F}=34.1, \mathrm{P}_{\mathrm{FDR}}=0.001$ ), and amendment-microhabitat combinations (pseudo-F $=1.9, \mathrm{P}_{\mathrm{FDR}}=0.001$ ) (Figure S3). All pairwise comparisons between amendments were significantly different from each other $\left(\mathrm{P}_{\mathrm{FDR}}=0.002\right)$. All but one of the microhabitats differed from one another $\left(\mathrm{P}_{\mathrm{FDR}} \leq 0.01\right)$. Specifically, the rhizoplane and endosphere communities were indistinguishable $\left(\mathrm{P}_{\mathrm{FDR}}=0.529\right)$.

Generally, the $16 \mathrm{~S}$ community became less diverse with closer proximity to the root. There were distinct differences in community composition among treatment and, furthermore, root microhabitat within each growing medium (Figure 4). Soils amended with $\mathrm{VC}$ had the most unique bacterial community. Total variation among treatments was slightly greater in soil than it was for the growing mix ("control"). Bacterial community composition differed most between growing mediums for the UC treatment and least for the PP treatment. 
UC

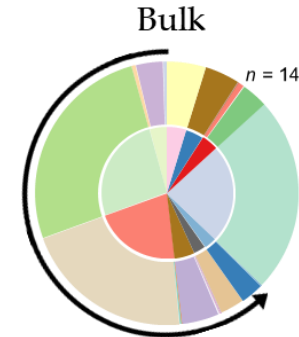

VC
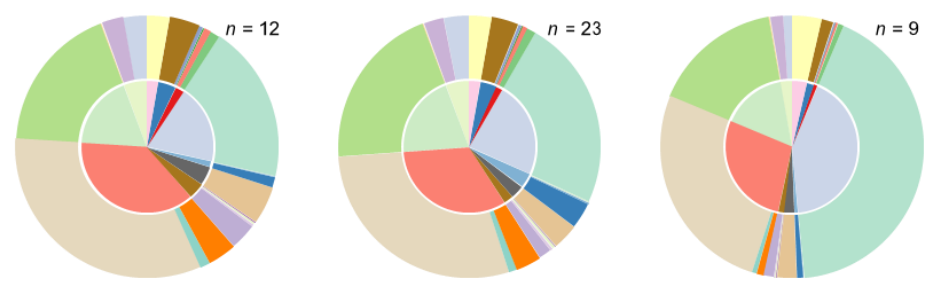

DMC
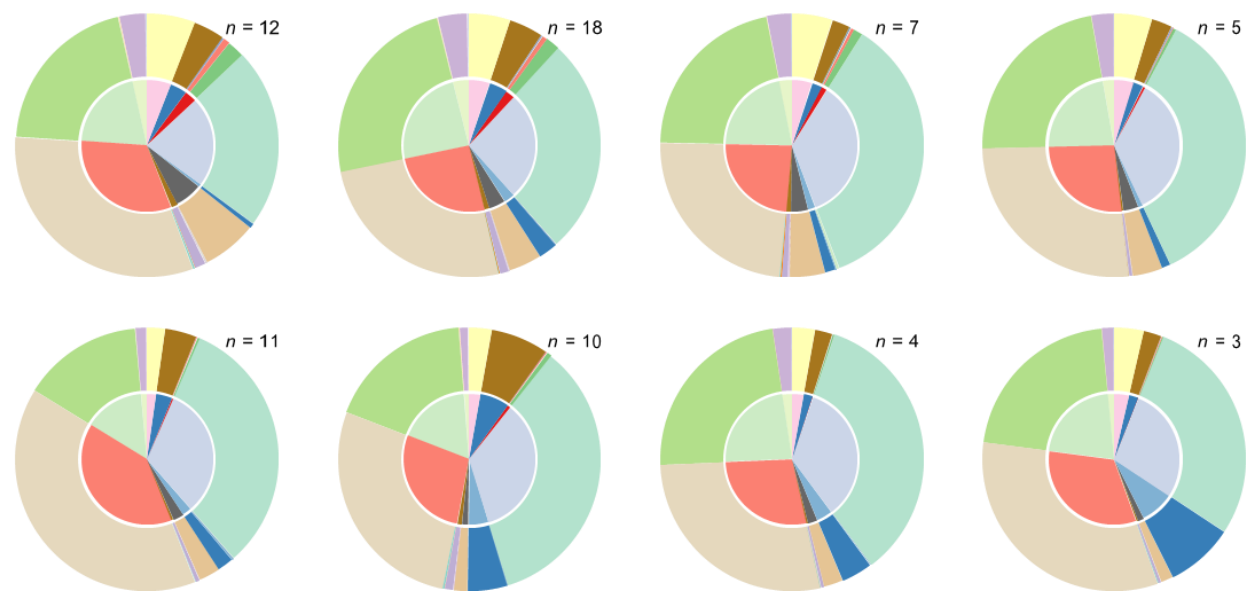

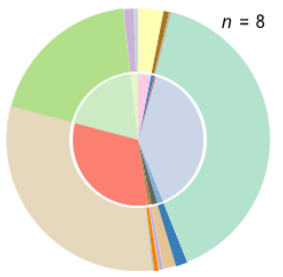

Endosphere
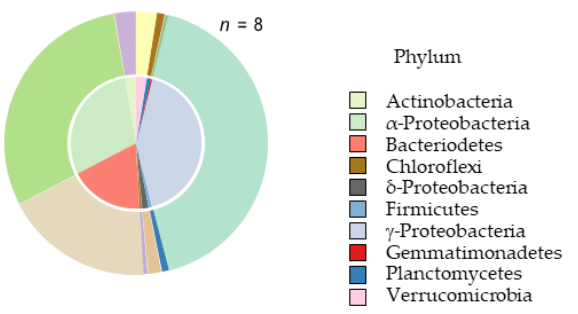

Acidimicrobiia

Actinobacteria

Nitriliruptoria

Rubrobacteria

Thermoleophilia

Thermoleophilia

$\alpha$-Proteobac
Bacteroidia

Ignavibacteria

Rhodothermia

AD3

Anaerolineae

Chloroflexia

Dehalococcoidia

Ktedonobacteria

N9D0

OLB14

TK10

$\delta$-Proteobacteria

Bacilli

Clostridia

Erysipelotrichia

Erysipelotrichi
Limnochordia

Negativicutes

-Proteobacteria

Gemmatimonadete

Longimicrobia

OM190

Phycisphaerae

Planctomycetacia
vadinHA49

Verrucomicrobiae

Figure 4. Community assembly of bacteria and archaea by $16 \mathrm{~S}$ amplicon sequencing for microhabitat (columns) for each of four treatments (rows). Microhabitats are illustrated by column: bulk soil, rhizosphere, rhizoplane, and endosphere. Treatments represent growing mix and soil with amendment of vermicompost (VC, 20\% v/v), dairy manure compost (DMC, 20\% v/v), or dehydrated poultry manure pellets (PP, 10\% v/v) compared to an untreated (conventional fertilizer) control (UC). 16S community composition is illustrated by taxonomic phyla (inner pie) and class (outer pie). Data presented represent pooled samples from all harvest times $(n=174)$. The arrow around the upper left pie indicates directionality of the legend (counterclockwise) and where the slices start (12 o'clock).

Bacterial community composition varied among microhabitats within each treatment (Figure 4). Root microhabitats within each treatment segregated into pairs: the bulk soil and rhizosphere communities, and the rhizoplane and endosphere communities. This pairing was distinct in all but one treatment, in which the rhizoplane and endosphere communities differed in soils amended with DMC. The rhizoplane and endosphere bacterial communities in amended soils varied more from those of the UC soil than did the bulk soil and rhizosphere bacterial communities.

Bacterial communities were dominated by the phyla Bacteroidetes and Proteobacteria. Proteobacteria were primarily from $\alpha$ - and $\gamma$-Proteobacteria classes (Table S1). The percentage of $\delta$-Proteobacteria was more similar to that of the other major phyla present: Acidobacteria, Actinobacteria, Chloroflexi, Firmicutes, Gemmatimonadetes, Planctomycetes, and Verrucomicrobia.

The UC treatment hosted the least abundance of Bacteroidetes and the greatest abundance of Proteobacteria (Figure 4). Organic amendments increased the abundance of Bacteroidetes. PP and VC amendment led to the first and second greatest abundance of Bacteroidetes, respectively. The third most abundant phylum explained $4 \%$ to $5 \%$ of 
the bacterial community in each treatment. The third most abundant phylum in the UC, VC, and DMC, and PP treatment was Firmicutes, Actinobacteria, Verrucomicrobia, and Planctomycetes, respectively (Figure 4).

Treatment differences were distinct at finer taxonomic resolution. Seven of the ten most abundant taxa were $\gamma$-Proteobacteria: Acinetobacter, Luteimonas, Rheinheimera, Pseudomonas, Steroidobacter, and two ESVs from the genus Massilia (Table 3) Two ESVs identified as Chryseolinea were the only representatives of the Bacteroidetes phylum. Devosia, the only representative of $\alpha$-Proteobacteria, was the most ubiquitous organism, present in 155 of 174 samples and amongst the 10 most abundant taxa in all treatments but the PP. Only Pseudomonas was amongst the 10 most abundant genera in all four treatments (Table 3).

Table 3. Ten most abundant $16 \mathrm{~S}$ ESV sidentified amongst all samples $(n=174)$.

\begin{tabular}{|c|c|c|c|c|c|}
\hline ESV ID & Phylum & Class & Order & Family & Genus \\
\hline ESV_5 & Bacteroidetes & Bacteroidia & Cytophagales & Microscillaceae & Chryseolinea \\
\hline ESV_6 & Proteobacteria & $\gamma$-Proteobacteria & Steroidobacterales & Steroidobacteraceae & Steroidobacter \\
\hline ESV_4 & Proteobacteria & $\gamma$-Proteobacteria & $\beta$-Proteobacteriales & Burkholderiaceae & Massilia \\
\hline ESV_3 & Proteobacteria & $\gamma$-Proteobacteria & $\beta$-Proteobacteriales & Burkholderiaceae & Massilia \\
\hline ESV_9 & Proteobacteria & $\alpha$-Proteobacteria & Rhizobiales & Devosiaceae & Devosia \\
\hline ESV_7 & Proteobacteria & $\gamma$-Proteobacteria & Alteromonadales & Alteromonadaceae & Rheinheimera \\
\hline ESV_13 & Bacteroidetes & Bacteroidia & Cytophagales & Microscillaceae & Chryseolinea \\
\hline ESV_11 & Proteobacteria & $\gamma$-Proteobacteria & Xanthomonadales & Xanthomonadaceae & Luteimonas \\
\hline ESV_12 & Bacteroidetes & Bacteroidia & Chitinophagales & Chitinophagaceae & Parafilimonas \\
\hline ESV_8 & Proteobacteria & $\gamma$-Proteobacteria & Pseudomonadales & Moraxellaceae & Acinetobacter \\
\hline ESV_10 & Proteobacteria & $\gamma$-Proteobacteria & Pseudomonadales & Pseudomonadaceae & Pseudomonas \\
\hline
\end{tabular}

The abundance of specific genera provided the greatest distinction among treatments. The most abundant genus in the UC treatment was Massilia. This genus accounted for less than $0.5 \%$ of the bacterial community in other treatments. The VC treatment hosted the greatest abundance of Rheinheimera and more than ten times the abundance of Chryseolinea of any other treatment. The DMC treatment hosted the greatest abundance of Asticcacaulis, Devosia, Luteimonas, and more than three times the abundance of Steroidobacter of any other treatment. The PP treatment had more than eight times the abundance of Acinetobacter of any other treatment. Amending with PP also led to the greatest abundance of Bacteroidetes genera of the orders Sphingobacteriales (Arcticibacter, Pedobacter, Sphingobacterium) and Flavobacteriales (Flavobacterium, Fluviicola) (Table S1).

\subsubsection{Plant Phenology}

Sampling each treatment before germination provided a baseline microbial community that was influenced by the presence of an actively growing seedling. The unamended growing mix was dominated by an unidentified genus from the Chitinophagaceae family. The abundance of this organism decreased in each of the amended treatments. The growing mix amended with VC hosted a greater abundance of Tumebacillus and Chryseolinea, whereas the growing mix amended with PP hosted a greater abundance of Acinetobacter and Streptomyces. Thirty days after germination, the growing mixes amended with VC, $\mathrm{DMC}$, and PP were distinguished by an abundance of Chryseolinea, Steroidobacter, and Roseimaritima, respectively.

Differences among treatments were even greater after transplant (Figure 4). Despite relatively little abundance in the growing mix, the UC treatment hosted the greatest abundance of Massilia after transplant to soil. Chryseolinea abundance continued to distinguish the VC treatment. Soil amended with DMC hosted the greatest abundance of Asticcacaulis and Devosia, whereas soil amended with PP was dominated by Acinetobacter. 


\subsubsection{Root Microhabitat}

The number of unique ESVs (taxonomic richness) was greatest in bulk soil and least in the root endosphere (Figure S2). The greatest variation in richness among organic amendments was in the rhizosphere. The proportion of the dominant phyla varied little among root microhabitat (Figure 4). Notably, $\gamma$-Proteobacteria were enriched with closer proximity to the root, whereas observation of this trend among other phyla was better depicted at finer resolution. The abundance of Proteobacteria, including Cellvibrio, Devosia, Pseudomonas, Rheinheimera, Shinella, and Stenotrophomonas, increased with closer proximity to the root (Table S2).

In the UC treatment, the abundance of Massilia in the rhizoplane and the endosphere was approximately four times that of the bulk and rhizosphere. In the DMC treatment, Pseudomonas and Stenotrophomonas were ten times and one hundred times more abundant, respectively, in the endosphere than bulk soil. Similarly, in the PP treatment, the abundance of Shinella and Stenotrophomonas increased linearly with closer proximity to the root. In contrast, several genera in the Bacteroidetes were more abundant in bulk and rhizosphere soil than they were inside roots or on the root surface. In the VC treatment, for example, Chryseolinea was more than twice as abundant in bulk and rhizosphere soils as it was on the rhizoplane.

\subsection{Fungal Community Composition}

The fungal community composition of the VC and DMC treatments were the least and most different from the UC, respectively (Figure 5, Figure S3). Regardless of treatment, fungal communities varied between endosphere and bulk soil or rhizosphere $\left(\mathrm{P}_{\mathrm{FDR}}=0.02\right)$, but were similar among other pairs of microhabitats $\left(\mathrm{P}_{\mathrm{FDR}}>0.1\right)$. The treatments that had the healthiest plants (UC, VC) went from most diverse in the bulk soil to being dominated by the same family (Nectriaceae) in the endosphere. Nectriaceae contains the genus Fusarium. The microbial communities were quite different in the DMC and PP treatments.

Fungal communities were dominated by Ascomycota, Mortierellomycota, and Basidiomycota (Table 4). In addition, there were small populations $(<1 \%)$ of Blastocladiomycota, Chytridiomycota, Mucoromycota, Rozellomycota, and Zoopagomycota. Amendments increased the abundance of Basidiomycota, especially DMC and VC (Table S3). The VC treatment also hosted a small population of Rozellomycota that was not found in any other treatments. DMC was the only amendment that increased Ascomycota abundance. PP was the only amendment to increase Mortierellomycota abundance, doing so considerably.

Mortierella was the most abundant genus in the UC and PP treatments (Table S3). The second most abundant genus in the UC treatment was Fusarium. This genus was moderately abundant in soils amended with $\mathrm{VC}$. The third most abundance genus in the UC treatment, Zopfiella, increased with the amendment of DMC. Amending with DMC introduced Scedosporium, a genus absent from the UC treatment. Amending with PP increased the abundance of Arthrobotrys, found in little abundance in the other treatments, and Cephaliophora, which was not present in any other treatments.

The unamended growing mix was dominated by Mortierellomycota, specifically Mortierella. Amendments increased the abundance of Ascomycota. Amending growing mix with DMC increased Basidiomycota and introduced Scedosporium, a genus that was absent from other treatments. Seed germination increased the abundance of Scedosporium, which carried over into soil after transplant. Ascomycota was the most abundant phylum in all soils after transplant. Amending soil with VC and PP increased the abundance of Basidiomycota, whereas PP-amended soil hosted the greatest abundance of Mortierellomycota. 

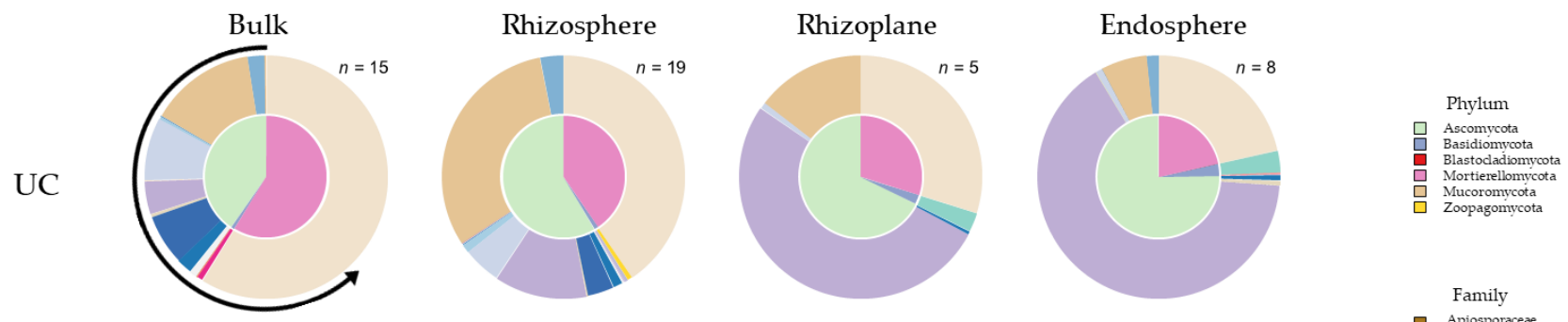

VC
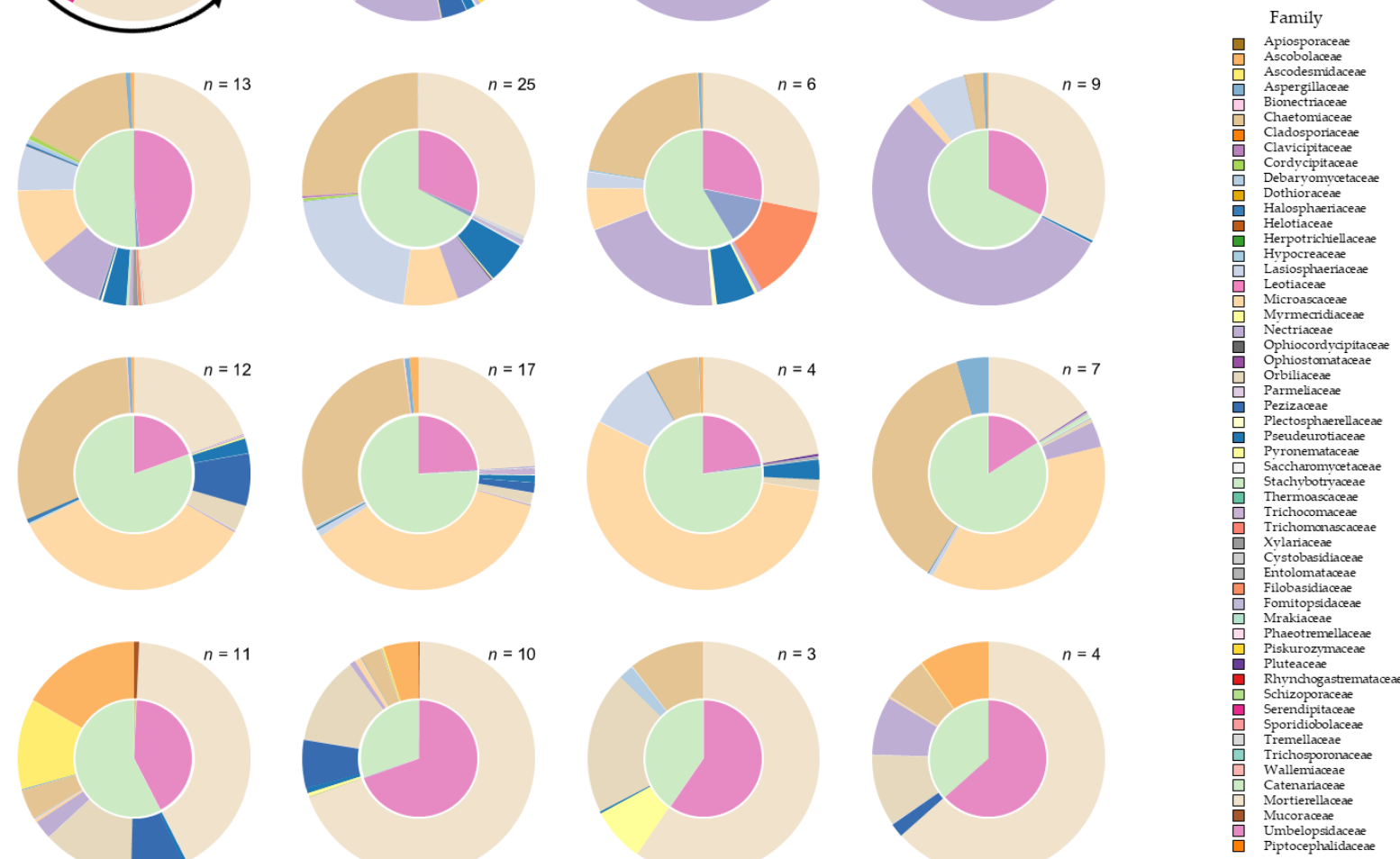

DMC
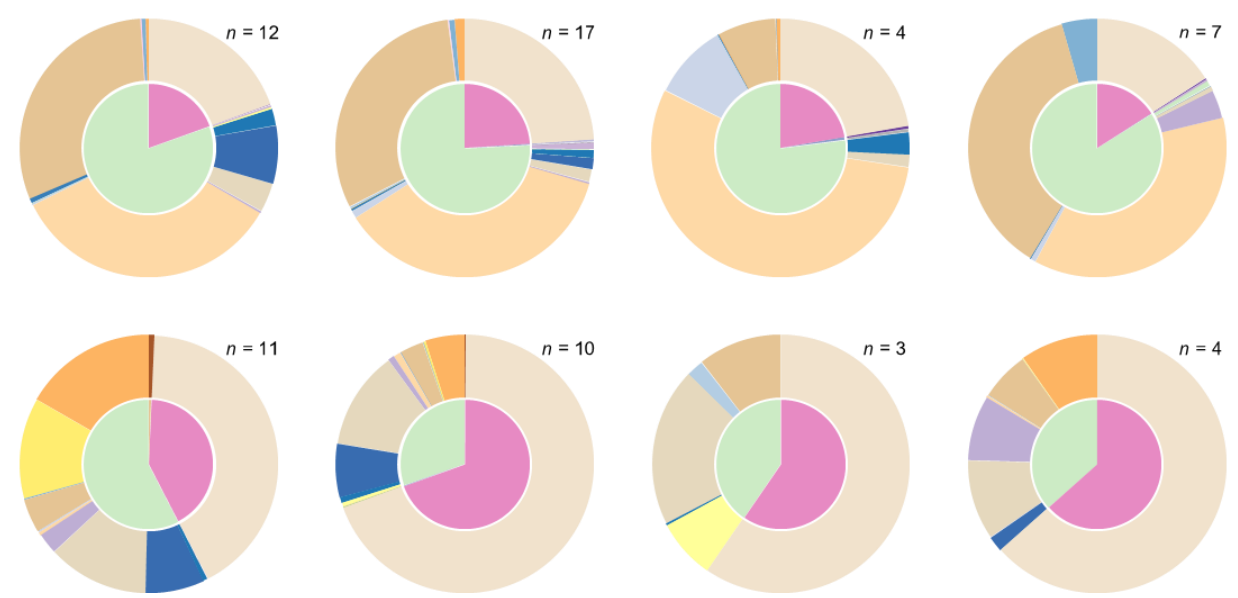

Figure 5. Community assembly of fungi by ITS amplicon sequencing for microhabitats (columns) for each of four treatments (rows). Microhabitats are illustrated by column: bulk soil, rhizosphere, rhizoplane, and endosphere. Treatments represent growing mix and soil with amendment of vermicompost (VC, 20\% v/v), dairy manure compost (DMC, 20\% v/v), or dehydrated poultry manure pellets (PP, $10 \% v / v$ ) compared to an untreated (conventional fertilizer) control (UC). Fungal community composition is illustrated by taxonomic phyla (inner pie) and family (outer pie). Data presented represent pooled samples from all harvest times $(n=168)$. The arrow around the upper left pie indicates directionality of the legend (counterclockwise) and where the slices start (12 o'clock).

Table 4. Ten most abundant ITS ESVs identified amongst all samples $(n=168)$.

\begin{tabular}{cccccc}
\hline ESV ID & Phylum & Class & Order & Family & Genus \\
\hline ESV_2 & Mortierellomycota & Mortierellomycetes & Mortierellales & Mortierellaceae & Mortierella \\
ESV_4 & Ascomycota & Sordariomycetes & Hypocreales & Nectriaceae & Fusarium \\
ESV_3 & Mortierellomycota & Mortierellomycetes & Mortierellales & Mortierellaceae & Mortierella \\
ESV_5 & Ascomycota & Sordariomycetes & Sordariales & Chaetomiaceae & Zopfiella \\
ESV_11 & Ascomycota & Sordariomycetes & Sordariales & Chaetomiaceae & Zopfiella \\
ESV_9 & Ascomycota & Sordariomycetes & Microascales & Microascaceae & Scedosporium \\
ESV_13 & Mortierellomycota & Mortierellomycetes & Mortierellales & Mortierellaceae & Mortierella \\
ESV_8 & Basidiomycota & Unknown & Unknown & Unknown & Unknown \\
ESV_12 & Ascomycota & Eurotiomycetes & Onygenales & Incertae sedis & Chrysosporium \\
ESV_6 & Mortierellomycota & Mortierellomycetes & Mortierellales & Mortierellaceae & Mortierella \\
ESV_2 & Mortierellomycota & Mortierellomycetes & Mortierellales & Mortierellaceae & Mortierella \\
\hline
\end{tabular}


Manure-derived amendments increased richness from the untreated control (Figure S2). Richness generally declined as microhabitat was in closer proximity to the root (Figure S2). Microhabitats were generally less distinct among fungal ESVs than among bacterial ESVs (Figures 4 and 5). In the UC treatment, Mortierella abundance was greatest in the bulk soil, whereas Fusarium was most abundant in closer proximity to the root (Table S4). Fusarium abundance followed a similar pattern in the VC treatment. Abundance of certain genera by microhabitat did not follow consistent patterns in soils amended with DMC or PP.

\section{Discussion}

Vermicompost promoted plant growth as much as the fertilizer controls. None of the composts received fertilizer inputs, suggesting vermicompost can obtain the results achieved by fertilizer, but without the fertilizer. This study demonstrates that vermicompost derived from dairy manure compost promotes plant growth more than traditional dairy manure compost and non-composted dehydrated poultry manure pellets. Bacterial and fungal communities in dairy manure compost-derived vermicompost are more mature and stable than those of dairy manure compost or poultry manure pellets [46,47] which correlates with less phytotoxicity [48]. This study contributes to the limited but developing knowledge of 16S and ITS communities associated with dehydrated poultry manure pellet and dairy manure-derived vermicompost amendment [31,33,36]. Poultry manure pellet amendment was inferior to both dairy manure-based products in this system. Despite its widespread use as a nitrogen-rich fertilizer, we found that poultry manure pellets dramatically altered the physical structure of soil to the extent that it impeded root growth. Furthermore, this study validates that the absence or insufficient duration of composting can result in a cascade of deleterious effects on crop and soil health $[37,49]$.

The communities sequenced in this study were dominated by bacteria of the phyla Bacteroidetes and Proteobacteria. Other studies conducted on tomato plants report a community dominated by Proteobacteria [50-54] and Ascomycota, the dominant fungal phylum in this study [53]. In addition, Bacteroidetes have been observed previously in similar abundance in the tomato rhizosphere [51,54]. Several of these studies also documented the presence of Acidobacteria, Actinobacteria, Bacteroidetes, Chloroflexi, Gemmatimonadetes, Firmicutes, and Verrucomicrobia.

\subsection{Soil Properties and Plant Growth}

Contrary to the existing literature, amendment with manure-derived fertilizers was detrimental to plant growth in this study. Plants grown in soils without these amendments displayed more advanced maturation and greater height, biomass, and root length density than those treated with these amendments. Increasing water holding capacity of soils treated with manure-derived fertilizer amendments was correlated with less root growth and total plant biomass. Of those treated with manure-derived fertilizers amendments, only VC led to vigorous growth through the duration of the experiment, whereas DMC had mixed impacts on plant growth and PP was detrimental. Through time, the difference among treatments increased as the health of plants in soils amended with DMC and PP declined. Variability in the nutrient composition of these amendments may have also contributed to plant growth differences and should be quantified to provide additional support for these findings.

Soil amended with VC held less moisture than those amended with DMC or PP and demonstrated superior root growth as a result. VC is a finely divided peat-like material with excellent structure, porosity, aeration, and drainage [10]. Combining composting and vermicomposting reduces the electrical conductivity and $\mathrm{C}$ to $\mathrm{N}$ ratio of the material, thus reducing phytotoxicity and $\mathrm{N}$ immobilization, respectively [46]. The vermicompost process also increases nitrogen availability to plants by enhancing the nitrification of ammonium to nitrate [47]. As a result, VC amendment consistently demonstrates impacts on plant growth similar to those of fertilizer controls [38]. 
In contrast, plants grown in soils amended with DMC demonstrated symptoms indicative of compost immaturity. Phytotoxicity of immature composts can manifest symptoms including stunting, chlorosis, and limited root development [49]. Decomposition of labile compounds in immature composts consumes oxygen and immobilizes nitrogen $[49,55]$. Depletion of oxygen can inhibit root function [56] and microbial demand for nitrogen can stunt plant growth [57]. Immature composts also contain volatile organic acids and free ammonia, which inhibit seed germination and root growth [49]. The duration of the maturation phase of a compost is fundamental to reducing phytotoxicity [49].

Amendment with PP reduced drainage and resulted in anaerobic conditions that led to a cascade of deleterious effects on plant growth and soil microbes. Oversaturation and poor drainage limit air-filled pore space, causing injury and inhibiting function of roots by oxygen deficiency [56]. These roots were further damaged by herbivory from fungus gnat larvae, which were abundant only in soil amended with PP. Anaerobic microsites created by PP amendment can also lead to the reduction of nitrogen to nitrogenous gas [49]. Increases in nitrous oxide [58,59] and ammonia [60] have been observed after amendment with poultry manure-based amendments. Direct inhibition of root growth by volatilized ammonia has been observed shortly after the application of poultry manure [61].

\subsection{Plant Phenology and Root Microhabitat}

Composition of microbial communities varied by plant phenology and microhabitat. The influence of treatment on microbial communities was evident immediately after amendment. Composition shifted with seed germination and seedling growth, demonstrating the ability of certain introduced taxa, including Scedosporium in the DMC treatment, to colonize the rhizosphere and sustain growth through time. Changes in microbial communities occur upon root emergence [62] and throughout plant development [63]. Rhizosphere community composition also differed between growing mix, before transplant, and field soil, after transplant, an observation that was recently made in tomato [54]. After transplant, with the decline of the DMC and PP treatments, the impact of active root growth and exudation on the microbial community [22] was evident in the presence (UC, VC) or absence (DMC, PP) of a rhizosphere effect [29]. These findings align with the notion that plant health status imposes significant influence on the rhizosphere microbial community [64].

Partitioning by microhabitat in this study is similar to previous reports for tomato [51-53], e.g., relative abundance of $\gamma$-Proteobacteria genus Pseudomonas near the root [52]. Pseudomonas are often recognized as plant growth-promoting rhizobacteria (PGPR) with biocontrol potential $[20,24,30,65]$. However, closely related species of Pseudomonas are also prolific pathogens [66]. Limitations to the methods do not provide sufficient information to determine the functional role of Pseudomonas in this study. Other $\gamma$-Proteobacteria observed in this study that have PGPR potential include Devosia [67] and Massilia [35,68].

\subsection{Treatment-Specific Microbial Communities}

Unamended soil hosted fewer $\gamma$-Proteobacteria than $\alpha$-Proteobacteria and fewer Bacteroidetes compared to soils treated with manure-derived fertilizer amendments. This finding coincides with the expected increase in Bacteroidetes abundance, and expected increase and decrease in $\gamma$-Proteobacteria and $\alpha$-Proteobacteria abundance, respectively, in composts [8]. The control treatment was also distinguished by comparatively high abundances of the bacteria Massilia and the fungi Mortierella and Fusarium. Massilia may function to promote plant growth [68] but its abundance is inversely impacted by organic amendment application [69]. Mortierella abundance in bulk and rhizosphere soil is correlated with healthy roots [70] and is relatively abundant in poultry litter compost [33].

The abundance of Fusarium, a genus known for its predominant role as a plant pathogen [71], was unexpected due to the vigorous plant growth and larger root mass observed of the two treatments (UC and VC) in which its abundance was greatest. VC samples hosted little Massilia abundance but shared a greater abundance of Mortierella relative to the other treatments. Interestingly, both Massilia [35,72] and Mortierella [73] 
have been implicated in the suppression of Fusarium and other plant pathogens. Massilia abundance in the UC treatment was greatest in the rhizoplane and endosphere samples, suggesting this organism may suppress Fusarium by competing for habitat and resources.

Despite being known primarily as a plant pathogen, Fusarium also contains species that are non-pathogenic, or biocontrol agents against pathogenic Fusarium wilt of tomato [74]. Given the absence of disease symptoms and the correlation between Fusarium abundance and increased plant biomass, the Fusarium spp. observed in this study is related to the F. fujikuroi species complex, which includes pathogenic and non-pathogenic strains that survive saprophytically and promotes plant growth $[75,76]$.

VC-amended samples had the greatest abundance of Bacteroidetes of each treatment. Bacteroidetes and Proteobacteria dominate vermicompost microbial communities [77] and are more abundant in dairy manure-derived VC than windrow or aerated static pile composting systems [8]. Passage of materials through the worm Eisenia fetida digestive tract selectively modifies bacterial communities [78], whereas secretion of mucus-covered fecal pellets increases soil aggregation and provides readily available carbon to increase soil microbial activity [79] and nutrient availability [47]. The genus distinguishing the VC treatment, Chryseolinea, is promoted by compost amendment [80] and seed-applied biostimulant application [81]. Chryseolinea demonstrates enrichment in tomato roots [82] and has also been implicated in pathogenic Fusarium suppression [83]. Organisms in the VC treatment that were abundant in the rhizoplane and endosphere, including Pseudomonas and Rheinheimera, have been isolated from vermicompost [84] and also demonstrate suppression against pathogenic Fusarium [85].

DMC amendment was distinguished by the abundance of organisms that may be associated with compost immaturity and manure feedstocks. These organisms include the bacteria Asticcacaulis and Steroidobacter, and fungi Zopfiella and Scedosporium. Asticcacaulis is a genus with an affinity for simple carbon sources [86] that are present in immature composts. Scedosporium is found abundantly during the early stages of mesophilic composting and absent in the mature product [87]. Zopfiella has been identified in compost recipes including manure [8] and Steroidobacter is among the most abundant genera in composts including dairy cow manure [88]. The abundance of these organisms supports the notion that this material was unsuitable for use as a soil amendment due to its immaturity.

Several genera favored in the PP treatment, including Fluviicola, Flavobacterium, and Pedobacter, are known to colonize soil amended with poultry manure-based amendments $[33,34]$. These bacteria of the orders Flavobacteriales and Sphingobacteriales, in addition to fungi of the phylum Mortierellomycota, are significantly more abundant in soils treated with poultry manure-based amendments than dairy manure-based amendments [34]. These organisms demonstrate copiotrophic lifestyles supported by the greater nitrogen content of poultry manure [34] and the labile nature of the non-composted PP product. The high nitrogen content of poultry manure-based amendments also supports the survival of human pathogenic bacteria in field environments [33], which can be transmitted to the consumer on fresh produce [89].

PP is a dehydrated product that is approved for organic production, which may give the impression that the product is physiochemically or biologically stable. However, our observations suggest that poultry manure pellets demonstrate properties similar to those of raw manure applied to soil. Some of the organisms associated with PP in this study and with poultry manure-based amendments in previous research $[33,34]$ are also associated with nitrogen volatilization [90], which occurs after the application of poultry manure to soil [58-61].

The most abundant ESV in the PP treatment, Acinetobacter, also colonizes poultry manure [91] and tomatoes grown in soil amended with PP [31]. The ability of Acinetobacter to outcompete other organisms has been observed in the tomato phyllosphere [52] and on tomato roots after infection with the pathogen Ralstonia solancearum [92]. Acinetobacter also includes anaerobic denitrifying species [93], which would coincide with the overly saturated growing environment observed of this treatment. 


\section{Conclusions}

This study suggests that plant growth is affected by application of organic amendments not only by the soil microbial communities introduced, but also due to a synergistic effect on the physical soil environment. Furthermore, there is a strong interaction between root growth and the spatial heterogeneity of soil and root-associated microbial communities. Greater use of composts made from manure converts organic waste to a useful resource that promotes vegetable production and reduces fossil fuel inputs. Compost is an important component of a sustainable agriculture, not only to close the nutrient loop, but also as a means to reduce the environmental footprint of animal-based agriculture [94].

The varied response to organic amendment application reflects the inherent variability among manure-derived fertilizers and the dramatic impact these differences have on plant growth, soil physical properties, and soil microbial community composition. Successful utilization of these products to improve soil health and crop production will require a concerted effort to more comprehensively characterize these materials and the microbial communities that result from their application to the soil environment. Although this study highlights the widespread need for this research, it also successfully demonstrates the value of vermicomposting to stabilize manure-derived fertilizer products. The greater adoption of vermicomposting as a compost curing phase would serve to provide growers with a reliable alternative to synthetic fertilizer for promoting plant and soil health.

Supplementary Materials: The following are available online at https:/ / www.mdpi.com/article/10 $.3390 /$ microorganisms $9081561 / \mathrm{s} 1$, Table S1: Median percentage of sequences of the most abundant classified bacteria by compost treatment, Table S2: Mean relative abundance of dominant bacterial genera in each root microhabitat, Table S3: Median percentage of sequences of the most abundant classified fungi by compost treatment, Table S4: Mean relative abundance of dominant fungal genera in each root microhabitat, Figure S1: Relationship between gravimetric water content and volumetric water content, Figure S2: Number of unique 16S and ITS ESVs per sample observed for each treatment by microhabitat, Figure S3: Principal coordinate analysis (PCoA) displaying Bray-Curtis dissimilarity of $16 \mathrm{~S}$ and ITS gene sequences.

Author Contributions: Conceptualization, T.R., D.A.N.; methodology, D.A.N.; formal analysis, T.R., T.A. and D.A.N.; investigation, T.R.; writing-original draft preparation, T.R. and D.A.N.; writingreview and editing, T.R., T.A. and D.A.N.; visualization, T.R., T.A. and D.A.N.; project administration, D.A.N.; funding acquisition, D.A.N. All authors have read and agreed to the published version of the manuscript.

Funding: This project was funded the Vermont Agricultural Experiment Station Competitive Hatch Program VT-H02110MS.

Institutional Review Board Statement: Not applicable.

Informed Consent Statement: Not applicable.

Data Availability Statement: Rarified/filtered data, metadata and fasta files for 16S and ITS amplicon sequences are archived for public access at https: / / doi.org/10.6084/m9.figshare.14731278.v1 (accessed on 21 July 2021), Data are also archived at the University of Colorado Sequencing Facility.

Acknowledgments: We thank Thomas R. Weicht for technical assistance in conceptualization and design of the experiment, and Noah Fierer's lab (University of Colorado at Boulder) for amplicon sequencing.

Conflicts of Interest: The authors declare no conflict of interest.

\section{References}

1. Brown, S. Greenhouse gas accounting for landfill diversion of food scraps and yard waste. Compost Sci. Util. 2016, 24, 11-19. [CrossRef]

2. Astill, G.; Minor, T.; Thornsbury, S. Changes in U.S. produce grower food safety practices from 1999 to 2016. Food Control 2019, 104, 326-332. [CrossRef]

3. Celestina, C.; Hunt, J.R.; Sale, P.W.G.; Franks, A.E. Attribution of crop yield responses to application of organic amendments: A critical review. Soil Tillage Res. 2019, 186, 135-145. [CrossRef] 
4. Cesarano, G.; De Filippis, F.; La Storia, A.; Scala, F.; Bonanomi, G. Organic amendment type and application frequency affect crop yields, soil fertility and microbiome composition. Appl. Soil Ecol. 2017, 120, 254-264. [CrossRef]

5. Bonanomi, G.; Lorito, M.; Vinale, F.; Woo, S.L. Organic amendments, beneficial microbes, and soil microbiota: Toward a unified framework for disease suppression. Annu. Rev. Phytopathol. 2018, 56, 1-20. [CrossRef] [PubMed]

6. Aggelides, S.M.; Londra, P.A. Effects of compost produced from town wastes and sewage sludge on the physical properties of a loamy and a clay soil. Bioresour. Technol. 2000, 71, 253-259. [CrossRef]

7. US Composting Council. Compost Definition. Available online: https://www.compostingcouncil.org/page/CompostDefinition (accessed on 4 June 2021).

8. Neher, D.A.; Weicht, T.R.; Bates, S.T.; Leff, J.W.; Fierer, N. Changes in bacterial and fungal communities across compost recipes, preparation methods, and composting times. PLoS ONE 2013, 8, e79512. [CrossRef] [PubMed]

9. Rittenhouse, T. Tipsheet: Compost. Available online: https://attra.ncat.org/product/tipsheet-compost/ (accessed on 4 June 2021).

10. Dominguez, J.; Edwards, C.A.; Subler, S. A comparison of vermicomposting and composting. BioCycle 1997, 38, 57-59.

11. US Department of Agriculture. Processed Animal Manures in Organic Crop Production; NOP 5006; USDA: Washington, DC, USA, 2011.

12. Kyakuwaire, M.; Olupot, G.; Amoding, A.; Nkedi-Kizza, P.; Basamba, T.A. How safe is chicken litter for land application as an organic fertilizer? A review. Int. J. Environ. Res. Public Health 2019, 16, 3521. [CrossRef]

13. Obi, M.E.; Ebo, P.O. The effects of organic and inorganic amendments on soil physical properties and maize production in a severely degraded sandy soil in southern Nigeria. Bioresour. Technol. 1995, 51, 117-123. [CrossRef]

14. Linn, D.M.; Doran, J.W. Effect of water-filled pore space on carbon dioxide and nitrous oxide production in tilled and nontilled soils. Soil Sci. Soc. Am. J. 1984, 48, 1267-1272. [CrossRef]

15. Pagliai, M.; Vittori Antisari, L. Influence of waste organic matter on soil micro-and macrostructure. Bioresour. Technol. 1993, 43, 205-213. [CrossRef]

16. Drenovsky, R.E.; Vo, D.; Graham, K.J.; Scow, K.M. Soil water content and organic carbon availability are major determinants of soil microbial community composition. Microb. Ecol. 2004, 48, 424-430. [CrossRef] [PubMed]

17. Saison, C.; Degrange, V.; Oliver, R.; Millard, P.; Commeaux, C.; Montange, D.; Le Roux, X. Alteration and resilience of the soil microbial community following compost amendment: Effects of compost level and compost-borne microbial community. Environ. Microbiol. 2006, 8, 247-257. [CrossRef]

18. Inbar, E.; Green, S.J.; Hadar, Y.; Minz, D. Competing factors of compost concentration and proximity to root affect the distribution of Streptomycetes. Microb. Ecol. 2005, 50, 73-81. [CrossRef] [PubMed]

19. Van Wees, S.C.M.; Van der Ent, S.; Pieterse, C.M.J. Plant immune responses triggered by beneficial microbes. Curr. Opin. Plant Biol. 2008, 11, 443-448. [CrossRef] [PubMed]

20. Lugtenberg, B.; Kamilova, F. Plant-growth-promoting rhizobacteria. Annu. Rev. Microbiol. 2009, 63, 541-556. [CrossRef]

21. Raaijmakers, J.M.; Paulitz, T.C.; Steinberg, C.; Alabouvette, C.; Moënne-Loccoz, Y. The rhizosphere: A playground and battlefield for soilborne pathogens and beneficial microorganisms. Plant Soil 2008, 321, 341-361. [CrossRef]

22. Bais, H.P.; Weir, T.L.; Perry, L.G.; Gilroy, S.; Vivanco, J.M. The role of root exudates in rhizosphere interactions with plants and other organisms. Annu. Rev. Plant Biol. 2006, 57, 233-266. [CrossRef] [PubMed]

23. Richardson, A.E.; Barea, J.-M.; McNeill, A.M.; Prigent-Combaret, C. Acquisition of phosphorus and nitrogen in the rhizosphere and plant growth promotion by microorganisms. Plant Soil 2009, 321, 305-339. [CrossRef]

24. Glick, B. Plant growth-promoting bacteria: Mechanisms and applications. Scientifica 2012, 2012, 963401. [CrossRef] [PubMed]

25. Verbon, E.H.; Liberman, L.M. Beneficial microbes affect endogenous mechanisms controlling root development. Trends Plant Sci. 2016, 21, 218-229. [CrossRef] [PubMed]

26. Marasco, R.; Rolli, E.; Ettoumi, B.; Vigani, G.; Mapelli, F.; Borin, S.; Abou-Hadid, A.F.; El-Behairy, U.A.; Sorlini, C.; Cherif, A. A drought resistance-promoting microbiome is selected by root system under desert farming. PLoS ONE 2012, 7, e48479. [CrossRef]

27. Hayat, R.; Ali, S.; Amara, U.; Khalid, R.; Ahmed, I. Soil beneficial bacteria and their role in plant growth promotion: A review. Ann. Microbiol. 2010, 60, 579-598. [CrossRef]

28. Pangesti, N.; Pineda, A.; Pieterse, C.M.; Dicke, M.; van Loon, J.J. Two-way plant mediated interactions between root-associated microbes and insects: From ecology to mechanisms. Front. Plant Sci. 2013, 4, 414. [CrossRef] [PubMed]

29. Reinhold-Hurek, B.; Bunger, W.; Burbano, C.S.; Sabale, M.; Hurek, T. Roots shaping their microbiome: Global hotspots for microbial activity. Annu. Rev. Phytopathol. 2015, 53, 403-424. [CrossRef]

30. Compant, S.; Clément, C.; Sessitsch, A. Plant growth-promoting bacteria in the rhizo- and endosphere of plants: Their role, colonization, mechanisms involved and prospects for utilization. Soil Biol. Biochem. 2010, 42, 669-678. [CrossRef]

31. Allard, S.M.; Walsh, C.S.; Wallis, A.E.; Ottesen, A.R.; Brown, E.W.; Micallef, S.A. Solanum lycopersicum (tomato) hosts robust phyllosphere and rhizosphere bacterial communities when grown in soil amended with various organic and synthetic fertilizers. Sci. Total Environ. 2016, 573, 555-563. [CrossRef]

32. Nuzzo, A.; Satpute, A.; Albrecht, U.; Strauss, S.L. Impact of soil microbial amendments on tomato rhizosphere microbiome and plant growth in field soil. Microb. Ecol. 2020, 80, 398-409. [CrossRef]

33. Neher, D.A.; Cutler, A.J.; Weicht, T.R.; Sharma, M.; Millner, P.D. Composts of poultry litter or dairy manure differentially affect survival of enteric bacteria in fields with spinach. J. Appl. Microbiol. 2019, 126, 1910-1922. [CrossRef] 
34. Neher, D.A.; Limoges, M.A.; Weicht, T.R.; Sharma, M.; Millner, P.D.; Donnelly, C. Bacterial community dynamics distinguish poultry compost from dairy compost and non-amended soils planted with spinach. Microorganisms 2020, 8, 1601. [CrossRef] [PubMed]

35. Bonanomi, G.; Alioto, D.; Minutolo, M.; Marra, R.; Cesarano, G.; Vinale, F. Organic amendments modulate soil microbiota and reduce virus disease incidence in the TSWV-tomato pathosystem. Pathogens 2020, 9, 379. [CrossRef] [PubMed]

36. Jack, A.L.H.; Rangarajan, A.; Culman, S.W.; Sooksa-Nguan, T.; Thies, J.E. Choice of organic amendments in tomato transplants has lasting effects on bacterial rhizosphere communities and crop performance in the field. Appl. Soil Ecol. 2011, 48, 94-101. [CrossRef]

37. Neher, D.A.; Fang, L.; Weicht, T.R. Ecoenzymes as indicators of compost to suppress Rhizoctonia solani. Compost Sci. Util. 2017, 25, 251-261. [CrossRef]

38. Blouin, M.; Barrere, J.; Meyer, N.; Lartigue, S.; Barot, S.; Mathieu, J. Vermicompost significantly affects plant growth: A metaanalysis. Agron. Sustain. Dev. 2019, 39, 34. [CrossRef]

39. Carini, P.; Marsden, P.J.; Leff, J.W.; Morgan, E.E.; Strickland, M.S.; Fierer, N. Relic DNA is abundant in soil and obscures estimates of soil microbial diversity. Nat. Microbiol. 2016, 2, 16242. [CrossRef]

40. Fittipaldi, M.; Nocker, A.; Codony, F. Progress in understanding preferential detection of live cells using viability dyes in combination with DNA amplification. J. Microbiol. Methods 2012, 91, 276-289. [CrossRef]

41. Lauber, C.L.; Hamady, M.; Knight, R.; Fierer, N. Pyrosequencing-based assessment of soil pH as a predictor of soil bacterial community structure at the continental scale. Appl. Environ. Microbiol. 2009, 75, 5111-5120. [CrossRef]

42. Callahan, B.J.; McMurdie, P.J.; Rosen, M.J.; Han, A.W.; Johnson, A.J.; Holmes, S.P. DADA2: High-resolution sample inference from Illumina amplicon data. Nat. Methods 2016, 13, 581-583. [CrossRef]

43. Martin, M. Cutadapt removes adapter sequences from high-throughput sequencing reads. EMBnet J. 2011, 17, 10-12. [CrossRef]

44. McDonald, D.; Price, M.N.; Goodrich, J.; Nawrocki, E.P.; DeSantis, T.Z.; Probst, A.; Andersen, G.L.; Knight, R.; Hugenholtz, P. An improved Greengenes taxonomy with explicit ranks for ecological and evolutionary analyses of bacteria and archaea. ISME J. 2012, 6, 610-618. [CrossRef] [PubMed]

45. Kõljalg, U.; Nilsson, R.H.; Abarenkov, K.; Tedersoo, L.; Taylor, A.F.S.; Bahram, M.; Bates, S.T.; Bruns, T.D.; Bengtsson-Palme, J.; Callaghan, T.M.; et al. Towards a unified paradigm for sequence-based identification of fungi. Mol. Ecol. $2013,22$. [CrossRef] [PubMed]

46. Lazcano, C.; Gomez-Brandon, M.; Dominguez, J. Comparison of the effectiveness of composting and vermicomposting for the biological stabilization of cattle manure. Chemosphere 2008, 72, 1013-1019. [CrossRef]

47. Lim, S.L.; Wu, T.Y.; Lim, P.N.; Shak, K.P. The use of vermicompost in organic farming: Overview, effects on soil and economics. J. Sci. Food Agric. 2015, 95, 1143-1156. [CrossRef]

48. Wichuk, K.M.; McCartney, D. Compost stability and maturity evaluation-A literature review. Can. J. Civil Eng. 2010, 37, 1505-1523. [CrossRef]

49. Bernal, M.P.; Alburquerque, J.A.; Moral, R. Composting of animal manures and chemical criteria for compost maturity assessment. A review. Bioresour. Technol. 2009, 100, 5444-5453. [CrossRef] [PubMed]

50. Qiao, J.; Yu, X.; Liang, X.; Liu, Y.; Borriss, R.; Liu, Y. Addition of plant-growth-promoting Bacillus subtilis PTS-394 on tomato rhizosphere has no durable impact on composition of root microbiome. BMC Microbiol. 2017, 17, 131. [CrossRef]

51. Kwak, M.J.; Kong, H.G.; Choi, K.; Kwon, S.K.; Song, J.Y.; Lee, J.; Lee, P.A.; Choi, S.Y.; Seo, M.; Lee, H.J.; et al. Rhizosphere microbiome structure alters to enable wilt resistance in tomato. Nat. Biotechnol. 2018, 36, 1117. [CrossRef]

52. Dong, C.J.; Wang, L.L.; Li, Q.; Shang, Q.M. Bacterial communities in the rhizosphere, phyllosphere and endosphere of tomato plants. PLoS ONE 2019, 14, e0223847. [CrossRef]

53. Lee, S.A.; Kim, Y.; Kim, J.M.; Chu, B.; Joa, J.H.; Sang, M.K.; Song, J.; Weon, H.Y. A preliminary examination of bacterial, archaeal, and fungal communities inhabiting different rhizocompartments of tomato plants under real-world environments. Sci. Rep. 2019, 9, 9300. [CrossRef]

54. Cheng, Z.; Lei, S.; Li, Y.; Huang, W.; Ma, R.; Xiong, J.; Zhang, T.; Jin, L.; Haq, H.U.; Xu, X.; et al. Revealing the variation and stability of bacterial communities in tomato rhizosphere microbiota. Microorganisms 2020, 8, 170. [CrossRef] [PubMed]

55. Ryckeboer, J.; Mergaert, J.; Vaes, K.; Klammer, S.; De Clercq, D.; Coosemans, J.; Insam, H.; Swings, J. A survey of bacteria and fungi occurring during composting and self-heating processes. Ann. Microbiol. 2003, 53, 349-410.

56. Drew, M.C. Oxygen deficiency and root metabolism: Injury and acclimation under hypoxia and anoxia. Annu. Rev. Plant Physiol. Plant Mol. Biol. 1997, 48, 223-250. [CrossRef] [PubMed]

57. Levy, J.S.; Taylor, B.R. Effects of pulp mill solids and three composts on early growth of tomatoes. Bioresour. Technol. 2003, 89, 297-305. [CrossRef]

58. Cabrera, M.; Chiang, S.; Merka, W.; Pancorbo, O.; Thompson, S. Nitrous oxide and carbon dioxide emissions from pelletized and nonpelletized poultry litter incorporated into soil. Plant Soil 1994, 163, 189-195. [CrossRef]

59. Nishizawa, T.; Quan, A.; Kai, A.; Tago, K.; Ishii, S.; Shen, W.; Isobe, K.; Otsuka, S.; Senoo, K. Inoculation with $\mathrm{N}_{2}$-generating denitrifier strains mitigates $\mathrm{N}_{2} \mathrm{O}$ emission from agricultural soil fertilized with poultry manure. Biol. Fertil. Soils 2014, 50, 1001-1007. [CrossRef]

60. Marshall, S.B.; Wood, C.W.; Braun, L.C.; Cabrera, M.L.; Mullen, M.D.; Guertal, E.A. Ammonia volatilization from tall fescue pastures fertilized with broiler litter. J. Environ. Qual. 1998, 1125-1129. [CrossRef]

61. Pan, W.L.; Madsen, I.J.; Bolton, R.P.; Graves, L.; Sistrunk, T. Ammonia/ammonium toxicity root symptoms induced by inorganic and organic fertilizers and placement. Agron. J. 2016, 108, 2485-2492. [CrossRef] 
62. Barret, M.; Briand, M.; Bonneau, S.; Preveaux, A.; Valiere, S.; Bouchez, O.; Hunault, G.; Simoneau, P.; Jacquesa, M.A. Emergence shapes the structure of the seed microbiota. Appl. Environ. Microbiol. 2015, 81, 1257-1266. [CrossRef]

63. Chaparro, J.M.; Badri, D.V.; Vivanco, J.M. Rhizosphere microbiome assemblage is affected by plant development. ISME J. 2014, 8 , 790-803. [CrossRef] [PubMed]

64. Huang, X.; Zhou, X.; Zhang, J.; Cai, Z. Highly connected taxa located in the microbial network are prevalent in the rhizosphere soil of healthy plant. Biol. Fertil. Soils 2019, 55, 299-312. [CrossRef]

65. Haas, D.; Defago, G. Biological control of soil-borne pathogens by fluorescent pseudomonads. Nat. Rev. Microbiol. 2005, 3, 307-319. [CrossRef]

66. Passera, A.; Compant, S.; Casati, P.; Maturo, M.G.; Battelli, G.; Quaglino, G.; Antonielli, L.; Salerno, D.; Brasca, M.; Toffolatti, S.L. Not just a pathogen? Description of a plant-beneficial Pseudomonas syringae strain. Front. Microbiol. 2019, 10, 1409. [CrossRef]

67. Rivas, R.; Velázquez, E.; Willems, A.; Vizcaíno, N.; Subba-Rao, N.S.; Mateos, P.F.; Gillis, M.; Dazzo, F.B.; Martínez-Molina, E. A new species of Devosia that forms a unique nitrogen-fixing root-nodule symbiosis with the aquatic legume Neptunia natans (L.f.) Druce. Appl. Environ. Microbiol. 2002, 68, 5217-5222. [CrossRef] [PubMed]

68. Qiao, C.; Penton, C.R.; Xiong, W.; Liu, C.; Wang, R.; Liu, Z.; Xu, X.; Li, R.; Shen, Q. Reshaping the rhizosphere microbiome by bio-organic amendment to enhance crop yield in a maize-cabbage rotation system. Appl. Soil Ecol. 2019, 142, 136-146. [CrossRef]

69. Ofek, M.; Hadar, Y.; Minz, D. Ecology of root colonizing Massilia (Oxalobacteraceae). PLoS ONE 2012,7 , e40117. [CrossRef] [PubMed]

70. Xu, L.; Ravnskov, S.; Larsen, J.; Nicolaisen, M. Linking fungal communities in roots, rhizosphere, and soil to the health status of Pisum sativum. FEMS Microbiol. Ecol. 2012, 82, 736-745. [CrossRef]

71. Dean, R.; Van Kan, J.A.; Pretorius, Z.A.; Hammond-Kosack, K.E.; Di Pietro, A.; Spanu, P.D.; Rudd, J.J.; Dickman, M.; Kahmann, R.; Ellis, J.; et al. The top 10 fungal pathogens in molecular plant pathology. Mol. Plant Pathol. 2012, 13, 414-430. [CrossRef] [PubMed]

72. Araujo, R.; Dunlap, C.; Barnett, S.; Franco, C.M.M. Decoding wheat endosphere-rhizosphere microbiomes in Rhizoctonia solaniinfested soils challenged by Streptomyces biocontrol agents. Front. Plant Sci. 2019, 10, 1038. [CrossRef]

73. Xiong, W.; Li, R.; Ren, Y.; Liu, C.; Zhao, Q.; Wu, H.; Jousset, A.; Shen, Q. Distinct roles for soil fungal and bacterial communities associated with the suppression of vanilla Fusarium wilt disease. Soil Biol. Biochem. 2017, 107, 198-207. [CrossRef]

74. Fuchs, J.G.; Moënne-Loccoz, Y.; Défago, G. Nonpathogenic Fusarium oxysporum strain Fo47 induces resistance to Fusarium wilt in tomato. Plant Dis. 1997, 81, 492. [CrossRef]

75. Amatulli, M.T.; Spadaro, D.; Gullino, M.L.; Garibaldi, A. Molecular identification of Fusarium spp. associated with bakanae disease of rice in Italy and assessment of their pathogenicity. Plant Pathol. 2010, 59, 839-844. [CrossRef]

76. Niehaus, E.M.; Munsterkotter, M.; Proctor, R.H.; Brown, D.W.; Sharon, A.; Idan, Y.; Oren-Young, L.; Sieber, C.M.; Novak, O.; Pencik, A.; et al. Comparative "omics" of the Fusarium fujikuroi species complex highlights differences in genetic potential and metabolite synthesis. Genome Biol. Evol. 2016, 8, 3574-3599. [CrossRef]

77. Dominguez, J.; Aira, M.; Kolbe, A.R.; Gomez-Brandon, M.; Perez-Losada, M. Changes in the composition and function of bacterial communities during vermicomposting may explain beneficial properties of vermicompost. Sci. Rep. 2019, 9, 9657. [CrossRef]

78. Gómez-Brandón, M.; Domínguez, J. Recycling of solid organic wastes through vermicomposting: Microbial community changes throughout the process and use of vermicompost as a soil amendment. Crit. Rev. Environ. Sci. Technol. 2014, 44, 1289-1312. [CrossRef]

79. Jack, A.L.H.; Thies, J.E. Compost and vermicompost as amendments promoting soil health. In Biological Approaches to Sustainable Soil Systems; Uphoff, N., Ed.; CRC Press: Boca Raton, FL, USA, 2006; pp. 453-466.

80. Milkereit, J.; Geisseler, D.; Lazicki, P.; Settles, M.L.; Durbin-Johnson, B.P.; Hodson, A. Interactions between nitrogen availability, bacterial communities, and nematode indicators of soil food web function in response to organic amendments. Appl. Soil Ecol. 2021, 157. [CrossRef]

81. Visioli, G.; Sanangelantoni, A.M.; Vamerali, T.; Dal Cortivo, C.; Blandino, M. 16S rDNA profiling to reveal the influence of seed-applied biostimulants on the rhizosphere of young maize plants. Molecules 2018, 23, 1461. [CrossRef] [PubMed]

82. Barajas, H.R.; Martinez-Sanchez, S.; Romero, M.F.; Alvarez, C.H.; Servin-Gonzalez, L.; Peimbert, M.; Cruz-Ortega, R.; Garcia-Oliva, F.; Alcaraz, L.D. Testing the two-step model of plant root microbiome acquisition under multiple plant species and soil sources. Front. Microbiol. 2020, 11, 542742. [CrossRef]

83. Ou, Y.; Penton, C.R.; Geisen, S.; Shen, Z.; Sun, Y.; Lv, N.; Wang, B.; Ruan, Y.; Xiong, W.; Li, R.; et al. Deciphering underlying drivers of disease suppressiveness against pathogenic Fusarium oxysporum. Front. Microbiol. 2019, 10, 2535. [CrossRef] [PubMed]

84. Pathma, J.; Sakthivel, N. Molecular and functional characterization of bacteria isolated from straw and goat manure based vermicompost. Appl. Soil Ecol. 2013, 70, 33-47. [CrossRef]

85. Raaijmakers, J.M.; Leeman, M.; Van Oorschot, M.; Van der Sluis, I.; Schippers, B.; Bakker, P.A. Dose-response relationships in biological control of Fusarium wilt of radish by Pseudomonas spp. Phytopathology 1995, 85, 1075-1080. [CrossRef]

86. Mello, B.L.; Alessi, A.M.; McQueen-Mason, S.; Bruce, N.C.; Polikarpov, I. Nutrient availability shapes the microbial community structure in sugarcane bagasse compost-derived consortia. Sci. Rep. 2016, 6, 38781. [CrossRef] [PubMed]

87. De Gannes, V.; Eudoxie, G.; Hickey, W.J. Insights into fungal communities in composts revealed by 454-pyrosequencing: Implications for human health and safety. Front. Microbiol. 2013, 4, 164. [CrossRef] [PubMed] 
88. Zhong, X.Z.; Ma, S.C.; Wang, S.P.; Wang, T.T.; Sun, Z.Y.; Tang, Y.Q.; Deng, Y.; Kida, K. A comparative study of composting the solid fraction of dairy manure with or without bulking material: Performance and microbial community dynamics. Bioresour. Technol. 2018, 247, 443-452. [CrossRef]

89. Chang, Q.; Wang, W.; Regev-Yochay, G.; Lipsitch, M.; Hanage, W.P. Antibiotics in agriculture and the risk to human health: How worried should we be? Evol. Appl. 2015, 8, 240-247. [CrossRef]

90. Hester, E.; Harpenslager, S.; van Diggelen, J.; Lamers, L.; Jetten, M.; Luke, C.; Lucker, S.; Welte, C. Linking nitrogen load to the structure and function of wetland soil and rhizosphere microbial communities. mSystems 2018, 3, e00214-e00217. [CrossRef]

91. Akinde, S.B.; Obire, O. Aerobic heterotrophic bacteria and petroleum-utilizing bacteria from cow dung and poultry manure. World J. Microbiol. Biotechnol. 2008, 24, 1999-2002. [CrossRef]

92. Kay, E.; Bertolla, F.; Vogel, T.M.; Simonet, P. Opportunistic colonization of Ralstonia solanacearum-infected plants by Acinetobacter sp. and its natural competence development. Microb. Ecol. 2002, 43, 291-297. [CrossRef] [PubMed]

93. Su, J.F.; Zheng, S.C.; Huang, T.1.; Ma, F.; Shao, S.C.; Yang, S.F.; Zhang, L.N. Characterization of the anaerobic denitrification bacterium Acinetobacter sp. SZ28 and its application for groundwater treatment. Bioresour. Technol. 2015, 192, 654-659. [CrossRef]

94. Willett, W.; Rockstrom, J.; Loken, B.; Springmann, M.; Lang, T.; Vermeulen, S.; Garnett, T.; Tilman, D.; DeClerck, F.; Wood, A.; et al. Food in the Anthropocene: The EAT-Lancet Commission on healthy diets from sustainable food systems. Lancet 2019, 393, 447-492. [CrossRef] 